\title{
Galanin-Expressing GABA Neurons in the Lateral Hypothalamus Modulate Food Reward and Noncompulsive Locomotion
}

\author{
Emily Qualls-Creekmore, ${ }^{1}$ Sangho Yu, ${ }^{1}{ }^{\circledR}$ Marie Francois, ${ }^{1}$ John Hoang, ${ }^{1}{ }^{\circledR C}$ Clara Huesing, ${ }^{1}$ Annadora Bruce-Keller, ${ }^{1}$ \\ DDavid Burk, ${ }^{2}$ Hans-Rudolf Berthoud, ${ }^{1}$ Christopher D. Morrison, ${ }^{1}$ and Heike Münzberg ${ }^{1}$ \\ ${ }^{1}$ Neurobiology of Nutrition and Metabolism, and ${ }^{2}$ Cell Biology and Bioimaging Core, Pennington Biomedical Research Center, Louisiana State University \\ System, Baton Rouge, Louisiana 70808
}

The lateral hypothalamus (LHA) integrates reward and appetitive behavior and is composed of many overlapping neuronal populations. Recent studies associated LHA GABAergic neurons (LHA ${ }^{G A B A}$ ), which densely innervate the ventral tegmental area (VTA), with modulation of food reward and consumption; yet, $\mathrm{LHA}^{G A B A}$ projections to the VTA exclusively modulated food consumption, not reward. We identified a subpopulation of LHA ${ }^{G A B A}$ neurons that coexpress the neuropeptide galanin ( $\mathrm{LHA}^{\mathrm{Gal}}$ ). These $\mathrm{LHA}^{\mathrm{Gal}}$ neurons also modulate food reward, but lack direct VTA innervation. We hypothesized that $\mathrm{LHA}^{\mathrm{Gal}}$ neurons may represent a subpopulation of LHA ${ }^{G A B A}$ neurons that mediates food reward independent of direct VTA innervation. We used chemogenetic activation of LHA ${ }^{\text {Gal }}$ or LHA ${ }^{\text {GABA }}$ neurons in mice to compare their role in feeding behavior. We further analyzed locomotor behavior to understand how differential VTA connectivity and transmitter release in these LHA neurons influences this behavior. LHA ${ }^{\text {Gal }}$ or LHA ${ }^{G A B A}$ neuronal activation both increased operant food-seeking behavior, but only activation of LHA ${ }^{G A B A}$ neurons increased overall chow consumption. Additionally, LHA ${ }^{\text {Gal }}$ or LHA ${ }^{\text {GABA }}$ neuronal activation similarly induced locomotor activity, but with striking differences in modality. Activation of LHA ${ }^{G A B A}$ neurons induced compulsive-like locomotor behavior; while LHA ${ }^{\text {Gal }}$ neurons induced locomotor activity without compulsivity. Thus, LHA ${ }^{\text {Gal }}$ neurons define a subpopulation of LHA ${ }^{G A B A}$ neurons without direct VTA innervation that mediate noncompulsive food-seeking behavior. We speculate that the striking difference in compulsive-like locomotor behavior is also based on differential VTA innervation. The downstream neural network responsible for this behavior and a potential role for galanin as neuromodulator remains to be identified.

Key words: compulsivity; DREADD; energy expenditure; feeding; locomotor activity; marble-burying test

Significance Statement

The lateral hypothalamus (LHA) regulates motivated feeding behavior via GABAergic LHA neurons. The molecular identity of $\mathrm{LHA}^{\text {GABA }}$ neurons is heterogeneous and largely undefined. Here we introduce LHA ${ }^{\text {Gal }}$ neurons as a subset of LHA ${ }^{\text {GABA }}$ neurons that lack direct innervation of the ventral tegmental area (VTA). LHA $^{\text {Gal }}$ neurons are sufficient to drive motivated feeding and locomotor activity similar to LHA ${ }^{G A B A}$ neurons, but without inducing compulsive-like behaviors, which we propose to require direct VTA innervation. Our study integrates galanin-expressing LHA neurons into our current understanding of the neuronal circuits and molecular mechanisms of the LHA that contribute to motivated feeding behaviors.

\section{Introduction}

The lateral hypothalamic area (LHA) is implicated in feeding, food reward, and other motivated behaviors. Early research es-

Received Jan. 18, 2017; revised April 26, 2017; accepted May 16, 2017.

Author contributions: E.Q.-C. and H.M. designed research; E.Q.-C., S.Y., M.F., J.H., C.H., A.B.-K., D.B., H.-R.B., C.D.M., and H.M. performed research; E.Q.-C., S.Y., M.F., J.H., C.H., A.B.-K., D.H.B., H.-R.B., C.D.M., and H.M. analyzed data; E.Q.-C., S.Y., M.F., C.H., H.-R.B., C.D.M., and H.M. wrote the paper.

This work was supported by American Heart Association Grant AHA053298N and National Institutes of Health (NIH) Grants P/F DK020572-30, R01-DK092587 (H.M.), P20-GM103528 (H.M. and S.Y.), and T32-DK064584 (EQC). This work used the facilities of the Cell Biology and Bioimaging Core, supported in part by the Centers of Biomedical Research Excellence (NIH Grant P20-GM103528) and the Clinical Nutritional Research Unit (NIH Grant 1P30DK072476) center grants from the NIH. Partial support was provided through the Animal Phenotyping Core sup- tablished that the LHA is necessary to maintain homeostatic feeding behaviors (Anand and Brobeck, 1951). Furthermore, rodents show impressive motivation to self-administer electric stimula- ported through National Institute of Diabetes and Digestive and Kidney Diseases Nutritional Obesity Research Centers Grant \#2P30 DK072476 ("Nutritional Programming: Environmental and Molecular Interactions") at the Pennington Biomedical Research Center. H.-R.B. was partially supported by NIH Grant R01-DK047348 and C.D.M. was partially supported by R01-DK105032.

The authors declare no competing financial interests.

Correspondence should be addressed to either Heike Münzberg, PhD, or Emily Qualls-Creekmore, PhD, Pennington Biomedical Research Center, Louisiana State University System, 6400 Perkins Road, Baton Rouge, LA 70808 E-mail: Heike.Munzberg@pbrc.edu or Emily.Qualls-Creekmore@pbrc.edu.

DOI:10.1523/JNEUROSCI.0155-17.2017

Copyright $@ 2017$ the authors $\quad 0270-6474 / 17 / 376053-13 \$ 15.00 / 0$ 
tions to the LHA (Olds and Milner, 1954) and the LHA is well established for its interaction with the mesolimbic dopamine reward circuitry in the brain (Peyron et al., 1998; Korotkova et al., 2003; Leinninger et al., 2009; Kempadoo et al., 2013). The LHA is a large region with a heterogeneous molecular makeup and a diverse pattern of inputs and outputs (Swanson et al., 2005; Hahn and Swanson, 2010; Bonnavion et al., 2016). Much research has focused on defining the molecular signature of LHA neurons and their neural projections that regulate feeding and food reward (Berthoud and Münzberg, 2011).

Recent studies have focused on GABAergic LHA (LHA ${ }^{G A B A}$ ) neurons and associated neural circuits for their involvement in feeding and especially food reward (Jennings et al., 2015; Nieh et al., 2015). Optogenetic and chemogenetic stimulation and inhibition of LHA ${ }^{\text {GABA }}$ neurons had opposing effects on operant food seeking and food consumption. Interestingly, in vivo visualization of LHA ${ }^{G A B A}$ neuronal activity highlighted that food-seeking versus food-consumption behaviors are represented by activation of anatomically distinct GABA populations (Jennings et al., 2015). Similarly, activation of all ventral tegmental area (VTA)-projecting LHA neurons enhanced sucrose seeking, while selective activation of VTA-projecting GABAergic LHA neurons promotes food consumption but not sucrose seeking (Nieh et al., 2015).

We recently described a subpopulation of LHA neurons that express the neuropeptide galanin $\left(\mathrm{LHA}^{\mathrm{Gal}}\right)$ together with leptin receptors and neurotensin (Berthoud and Münzberg, 2011; Laque et al., 2013). These $\mathrm{LHA}^{\mathrm{Gal}}$ neurons modulate food reward without promoting overall food consumption (Laque et al., 2015). Also, $\mathrm{LHA}^{\text {Gal }}$ neurons do not project to the VTA, but instead innervate the locus ceruleus (LC) and local LHA neurons (Laque et al., 2015). Galanin often acts as an inhibitory neuropeptide, and many galanin neurons coexpress the inhibitory neurotransmitter GABA (Melander et al., 1986; Sherin et al., 1998). Thus, we hypothesized that LHA ${ }^{\text {Gal }}$ neurons may represent a distinct subset of LHA ${ }^{G A B A}$ neurons that selectively modulates food reward, but not overall food consumption.

To test this hypothesis, we compared operant food-seeking behavior and overall chow consumption following chemogenetic activation of $\mathrm{LHA}^{\mathrm{Gal}}$ neurons or LHA ${ }^{\mathrm{GABA}}$ neurons. Here we show that LHA ${ }^{\mathrm{Gal}}$ neurons are sufficient to promote operant food seeking, while overall chow consumption remained unchanged. In addition, we discovered that activation of $\mathrm{LHA}^{\text {Gal }}$ or LHA ${ }^{\text {GABA }}$ neurons robustly enhanced locomotor activity, but that GABA-induced hyperactivity was associated with a striking, compulsive-like behavior not observed with $\mathrm{LHA}^{\mathrm{Gal}}$ neuron-induced hyperactivity.

Thus, our data suggest that $\mathrm{LHA}^{\text {Gal }}$ neurons represent a subpopulation of LHA ${ }^{G A B A}$ neurons that promotes food reward independent of direct VTA innervation, while VTA innervating LHA $^{G A B A}$ neurons may be required to induce overall chow consumption. Furthermore, we show that targeting exclusively galanin-expressing LHA neurons attenuates compulsive-like locomotor behavior, while maintaining food-seeking behavior. The clear behavioral distinction of molecularly defined subsets of LHA $^{G A B A}$ neurons could have important implications for treatment strategies of feeding and psychiatric disorders.

\section{Materials and Methods}

\section{Animals}

All experimental procedures were approved by the Institutional Animal Care and Use Committee at the Pennington Biomedical Research Center. Mice were bred and housed at $22^{\circ} \mathrm{C}$ on a $12 \mathrm{~h} \mathrm{light/dark} \mathrm{cycle.} \mathrm{Food} \mathrm{and}$ water were available ad libitum unless otherwise specified. $\mathrm{Gal}^{\mathrm{Cre}}$ mice were generated in house as previously described (Laque et al., 2015) and
Vgat ${ }^{C r e}$ mice were generously provided by Dr. Bradford B. Lowell, Beth Israel Deaconess Medical Center and Harvard Medical School (Vong et al., 2011). Experimental animals were bred and used from homozygous breeding colonies. $\mathrm{Gal}^{\mathrm{TgGFP}} / \mathrm{Vgat}{ }^{\mathrm{Tom}}$ mice were generated by crossbreeding Gal ${ }^{\text {TgGFP }}$ mice [Stock Tg(Gal-EGFP)109Gsat, \#0163420UCD, Mutant Mouse Regional Resource Center; Laque et al., 2013] with Vgat ${ }^{\mathrm{Cre}}$ mice and Rosa-tomato ${ }^{\mathrm{f} / \mathrm{f}}$ mice [B6.Cg-Gt(ROSA)26Sor $<$ tm14(CAG-tdTomato)Hze>/J, Jackson Laboratory, stock \#007914] and were used for histology and cell-count experiments as hemizygous $\mathrm{Gal}^{\mathrm{TgGFP}}$, double heterozygous Vgat $^{T o m}$ mice.

\section{Genotyping}

Genotype for experimental animals was determined by PCR using the following primers: $\mathrm{Gal}^{\mathrm{Cre}}$ : cre, forward, $5^{\prime}$-CCT CTC CAC CCA AGC GGC CGG AGA ACC-3'; cre, reverse, $5^{\prime}$-CCG GCT CCG TTC TTT GGT GGC CCC TTC GCG-3'; wild type, forward, 5' -TCC TGA GAC CAT GTC CAC TG-3'; wild type, reverse, $5^{\prime}$-CTG CCA CTC CTG TGA TCT GA-3'; Vgat ${ }^{\mathrm{Cre}}$ : wild type, forward, 5'-CTT CGT CAT CGG CGG CAT TCT G-3'; wild type, reverse, 5' -CAG GGC GAT GTG GAA TAG AAA3'; cre, reverse, 5'-ATC GAC CGG TAA TGC AGG CAA-3'; Gal ${ }^{\text {TgGFP }}$ forward, 5'-TAT ATC ATG GCC GAC AAG CA-3'; reverse, 5'-GAA CTC CAG CAG GAC CAT GT-3'; Rosa-tomato ${ }^{\mathrm{f} / \mathrm{f}}$ : wild type, forward, 5'-AAG GGA GCT GCA GTG GAG TA-3'; wild type, reverse, 5' -CCG AAA ATC TGT GGG AAG TC-3': loxP, forward, 5'-GGC ATT AAA GCA GCG TAT CC-3'; loxP, reverse, 5' -CTG TTC CTG TAC GGC ATG G-3'.

\section{Stereotaxic surgery}

Viral injections were done as described previously (Rezai-Zadeh et al., 2014); briefly, mice were anesthetized using inhaled isofluorane $(2 \%$ isofluorane/1 $\mathrm{L} \mathrm{O}_{2} / \mathrm{min}$ ) and mounted into a stereotaxic frame (Stereotaxic Alignment System, Kopf Instruments) to enhance anatomically reproducible injections into the LHA $( \pm 0.9 \mathrm{~mm}$ lateral, $-1.35 \mathrm{~mm}$ cau$\mathrm{dal}$, and $-5.4 \mathrm{~mm}$ ventral to bregma based on the Paxinos mouse-brain atlas; Paxinos and Franklin, 2004). Either AAV5-hSyn-DIO-hM3DqmCherry [DREADD (designer receptor exclusively activated by designer drugs)-Gq, titer $6 \times 10^{12} \mathrm{cfu} / \mathrm{ml}$ ] or AAV5-hSyn-DIO-mCherry (control, titer $6 \times 10^{12} \mathrm{cfu} / \mathrm{ml}$ ) were injected bilaterally ( $200 \mathrm{nl}$ per site at a rate of $20 \mathrm{nl} / 30 \mathrm{~s}$ ) into the LHA. Guide cannula and injector remained in place for $5 \mathrm{~min}$ following injection to allow for diffusion into the parenchyma and to prevent backflow up the cannula tract. Skull access holes were filled using bone wax (Lukens, \#901) and the incision was closed with stainless steel wound clips (CellPoint Scientific, \#203-1000) and postoperative care was given (bupivicaine/lidocaine: $2.5-12.5 \mathrm{mg} / \mathrm{kg}$ once at incision; carprofen: $5 \mathrm{mg} / \mathrm{kg}$ once daily for $72 \mathrm{~h}$; once warm saline, i.p.). Mice recovered for $2-3$ weeks to allow sufficient viral expression before further experimental testing.

Two cohorts of virus-expressing mice were generated. Cohort 1 had exclusively male mice (Gal ${ }^{C r e}: n=4$ control, $n=9$ DREADD-Gq; Vgat ${ }^{C r e}: n=$ 4 control, $n=8$ DREADD-Gq virus), Cohort 2 had mixed male and female mice ( $\mathrm{Gal}^{\mathrm{Cre}}$ : control virus, $n=3$ males, 3 females; DREADD-Gq virus, $n=$ 4 males, 5 females).

\section{Behavioral experiments}

Clozapine- $\mathrm{N}$-oxide dose selection. Initial repeatable measurements, such as those related to locomotor activity, energy expenditure, and food intake, were performed with multiple doses of the designer drug clozapine$\mathrm{N}$-oxide (CNO; ligand for the DREADD-Gq receptor) to identify the most efficient $\mathrm{CNO}$ dose. Nonrepeatable behavioral experiments (operant conditioning, ensure intake, marble burying) were performed with a single CNO dose $(1 \mathrm{mg} / \mathrm{kg})$, which has been also used by several other studies (Jennings et al., 2015; Nakajima et al., 2016). For LHA ${ }^{\text {Vgat }}$ operant testing experiments, $1 \mathrm{mg} / \mathrm{kg}$ CNO induced excessive compulsive behaviors (gnawing) in all animals and interfered with the mouse's ability to perform the operant task. Thus, all LHA ${ }^{\text {Vgat }}$ mice were tested at multiple CNO doses $(0.1-1 \mathrm{mg} / \mathrm{kg})$ to identify individual CNO doses where mice were able to properly perform the operant task. For the marble burying, which can be only performed once, we chose the lowest CNO dose $(0.1$ $\mathrm{mg} / \mathrm{kg}$ ) tested, to minimize excessive compulsive behavior. 
Metabolic parameters. Animals from cohort 1 were adapted to metabolic chambers (TSE Systems) for 1 week before data were collected for locomotor activity (beam breaks) and oxygen consumption $\left(\mathrm{VO}_{2} \mathrm{ml} /\right.$ $\mathrm{kg} / \mathrm{h}$ ) in $30 \mathrm{~min}$ intervals. For stimulation experiments, animals were intraperitoneally injected with PBS or CNO $(0.1 \mathrm{mg} / \mathrm{kg}$ or $1 \mathrm{mg} / \mathrm{kg})$ at $\sim 1000 \mathrm{~h}$.

Locomotor activity was also measured with subcutaneously implanted telemetric radio transmitters (G2 E-Mitter, Starr Life Sciences), detected with individual receivers (Series 4000, Starr Life Sciences), and recorded with VitalView software (Starr Life Sciences). Telemetric radio transmitters were surgically implanted on the dorsal surface of each mouse in the interscapular area. Mice recovered for $\geq 1$ week before measurement of locomotor activity via telemetry. Measurements occurred in the home cage and, for neuronal stimulation experiments, mice were intraperitoneally injected with PBS or CNO $(0.1 \mathrm{mg} / \mathrm{kg}$ or $1 \mathrm{mg} / \mathrm{kg}$, i.p. $)$ at $\sim 1000$ Zeitgeber time and locomotor activity was recorded continuously (every minute) for $24 \mathrm{~h}$.

Motivated food intake. DREADD-Gq animals from cohort 1 ( $n=8$ per genotype) were food-restricted during the training phase of the experiment. This greatly facilitates operant conditioning learning by encouraging exploratory behavior and increasing motivation to work for food. Food restriction started 2 weeks before the operant training session with 2.5-3.5 g/d standard laboratory chow (Laboratory Rodent Diet 5001, LabDiet; distributed during the light cycle at 1200 Zeitgeber time) until animals reached $90 \%$ of their baseline body weight. Operant conditioning chambers (Med Associates) were $\sim 15.9 \times 14.0 \times 12.7 \mathrm{~cm}$, with a house light, wire bar floor, two lighted nose-poke holes with infrared beams, and a pellet dispenser that released reward pellets into a hopper located between the nose-poke holes. Mice were acclimated to sucrose reward pellets in their home cage $2 \mathrm{~d}$ before operant training to prevent neophobia. Training occurred in the following four steps with illuminated nose-poke holes marking the "correct" (rewarded) hole: Step 1-autoshaping: one reward per nose poke, both holes are marked correct; Step 2-fixed ratio 1 (FR1): one reward per one correct nose poke, only one hole is marked correct; Step 3-fixed ratio 5 (FR5): one reward per five consecutively correct nose pokes, only one hole is marked correct; Step 4 -progressive ratio (PR): one reward per increasing consecutive correct nose pokes on an exponential scale (i.e., 1, 2, 4, 6, 9, 12, 15, 20, 25, 32, 40, 50, 62, 77, 95, $118 \ldots$. ; Richardson and Roberts, 1996). Autoshaping was performed for $1 \mathrm{~d}$ in a $30 \mathrm{~min}$ session to acclimate the mice to the chambers and reinforce nose-poke behavior; FR1, FR5, and PR training were each performed daily for 5-7 d until mice achieved stable performance ( $\leq 10 \%$ variation in number of correct nose pokes and a 3:1 ratio of correct/incorrect responses over a $3 \mathrm{~d}$ period). Fixed ratio training consisted of $30 \mathrm{~min}$ sessions and PR sessions were $60 \mathrm{~min}$ or ended when the mouse did not complete any nose poke for a $5 \mathrm{~min}$ period (break point). Once training was completed, mice were returned to ad libitum feeding until returning to baseline bodyweight. PR testing occurred during the light cycle at 1200 Zeitgeber time. Stimulation of virally infected neurons was done with intraperitoneal injections of PBS or $\mathrm{CNO}$ at doses from 0.05 to $1 \mathrm{mg} / \mathrm{kg}$ body weight $1 \mathrm{~h}$ before PR testing. Data used for analysis included the total number of correct nose pokes (collectively leading to reward), total number of incorrect nose pokes (not leading to reward), and total number of rewards achieved during the PR testing session.

Palatable food intake. Mice from cohort 1 had access to a liquid palatable diet (Ensure, $97 \mathrm{kcal} / \mathrm{ml}$ ) for $1 \mathrm{~h}$ daily over $5 \mathrm{~d}$. On day 4 and 5, mice received counterbalanced intraperitoneal injections of either PBS or $\mathrm{CNO}(0.1 \mathrm{or} 1 \mathrm{mg} / \mathrm{kg}$ body weight) $1 \mathrm{~h}$ before Ensure access; intake (in grams) was measured following each training or testing session.

Chow intake. Intake (in grams) of standard laboratory chow (Purina 5001) was measured in metabolic cages (TSE Systems) and analyzed as cumulative food intake for 3 and $24 \mathrm{~h}$ following intraperitoneal injection of either PBS or CNO (dose range of $0.1-1 \mathrm{mg} / \mathrm{kg}$ body weight).

Marble-burying test. Standard mouse cages were filled with fresh bedding to a depth of $5 \mathrm{~cm}$ and 16 marbles $(\sim 1 \mathrm{~cm}$ diameter) were evenly spaced across the bedding. Vgat ${ }^{\text {Cre }}$ mice from cohort 1 ( $n=4$ control, $n=8$ DREADD-Gq) and $\mathrm{Gal}^{\mathrm{Cre}}$ mice from cohort 2 ( $n=6$ control, $n=$ 9 DREADD-Gq) were placed in the cage for $30 \mathrm{~min}$ and allowed to ambulate freely. Injection of CNO (1 mg/kg in $\mathrm{Gal}^{\text {Cre }}$ mice, $0.1 \mathrm{mg} / \mathrm{kg}$ in $\mathrm{Vgat}^{\mathrm{Cre}}$ mice) was administered $1 \mathrm{~h}$ before beginning the test. Please note, the marble-burying test in part reflects the animal's response to a novel environment and is therefore only testable once per animal. Thus, in this test we compared DREADD animals to a control virus group also treated with CNO. A repeated PBS control injection would have confounded the novelty of the marble-burying test. A photograph was taken of the cage before and after the mouse was in the cage and data were analyzed to determine the percentage of marbles buried while the mouse occupied the cage. ImageJ (Abramoff et al., 2004) was used to quantify the visible marble area in each photograph before and after the test. Data were expressed as percentage area buried after testing time to reflect changes in compulsive-like behaviors (Angoa-Perez et al., 2013).

\section{Perfusion and immunohistochemistry}

Two hours before perfusion, mice were injected with $\mathrm{CNO}(0.1 \mathrm{mg} / \mathrm{kg}$ or $1 \mathrm{mg} / \mathrm{kg}$, i.p.) for later histochemical confirmation of CNO-induced neural activation as indicated by induction of the early-response gene $c F o s$ (Rezai-Zadeh et al., 2014; Yu et al., 2016). Mice were deeply anesthetized and transcardially perfused with ice-cold saline followed by $10 \%$ formalin. Brains were harvested, postfixed in $10 \%$ formalin for $24 \mathrm{~h}$, and then transferred into $30 \%$ sucrose for cryopreservation until sectioning into four representative series ( $30 \mu \mathrm{m}$ per section) throughout the brain using a sliding microtome. One (of four) series of brain sections was processed using free-floating immunohistochemistry. Sections were pretreated with $1 \% \mathrm{H}_{2} \mathrm{O}_{2}$ in methanol, $0.3 \%$ glycine, and $0.03 \%$ SDS, before blocking in $3 \%$ normal donkey serum, followed by incubation in primary antibody, goat anti-c-Fos (1:200; Santa Cruz Biotechnology). Staining was developed with the Vectastain Elite ABC kit (Vector Laboratories) and 3,3'-diaminobenzidine tetrahydrochloride kit (Metal-Enhanced DAB Substrate Kit, Life Technologies) according to the manufacturers' specification. After that, mCherry was further stained with rabbit antidsRed (1:1000; Clontech) and detected with fluorescent-labeled secondary antibody (1:200; Alexa Fluor 594 donkey anti-rabbit, Thermo Fisher Scientific). Brains from $\mathrm{Gal}^{\mathrm{TgGFP}} / \mathrm{Vgat}^{\mathrm{Tom}}$ mice $(n=4)$ were stained for GFP using chicken anti-GFP (1:1000; Abcam) and detected with fluorescent-labeled secondary antibody (1:200; Alexa Fluor 488 donkey anti-chicken, Jackson ImmunoResearch Laboratories) and tdTomato was stained for with rabbit anti-dsRed (1:1000; Clontech), which was detected with fluorescent-labeled secondary antibody (1:200; Alexa Fluor 594 donkey anti-rabbit, Thermo Fisher Scientific).

\section{Cell counts}

For quantification of colocalization of galanin and Vgat (marker for GABA), we counted the number of galanin neurons colocalized with Vgat. Within the LHA, galanin is concentrated around the fornix [perifornical area (PFA)], and also in the anterior lateral LHA (indicated as LHA). For cell counting, we sampled both of these regions, which are located in two anatomical sections rostrocaudally. Images of LHA and PFA regions were collected using a Leica SP5 confocal microscope with 488 and $594 \mathrm{~nm}$ lasers in sequential scanning mode. HyD detector gain was fixed for all samples, $z$-section thickness was fixed at $2.6 \mu \mathrm{m}$ per step, and the zoom was fixed at $1.4 \times$. The microscope had a $20 \times, 0.70$ numerical aperture, dry objective. Brightness and contrast were modified with identical settings (Adobe Photoshop, Adobe Systems) between brains to better visualize GFP and tdTomato staining. We first counted the total galanin-GFP-expressing neurons, and performed a second count of galanin-GFP neurons also expressing tdTomato.

\section{Data analysis}

Statistical differences were analyzed using SigmaPlot (Systat Software). Analysis included paired and independent $t$ tests, two-way ANOVA, and two-way repeated-measures ANOVA as further indicated in figure legends. For datasets that did not follow a normal distribution, nonparametric analyses were applied using the Mann-Whitney rank sum test. A $p$ value $<0.05$ was considered statistically significant and denoted as follows: ${ }^{\star} p<0.05,{ }^{* *} p<0.01,{ }^{* *} p<0.001$. 


\section{Results}

Galanin neurons in the LHA are partially GABAergic

The neuropeptide galanin acts mostly inhibitory and galanin-expressing neurons are often GABAergic. To directly address the molecular identity of LHA $^{\text {Gal }}$ neurons, we generated double reporter mice ( Gal $^{\mathrm{TgGFP}} /$ Vgat $^{\text {Tom }}$ mice, $n=4 ; 1$ male, 3 females) with transgenic GFP expression in galanin neurons (Laque et al., 2013) and conditional tdTomato expression in vesicular GABA transporter (Vgat)positive neurons (Vong et al., 2011). We found that approximately half of LHA $(45 \pm 9 \%)$ and $\sim 30 \pm 6 \%$ of PFA galanin neurons were GABAergic neurons and that GABAergic galanin neurons represent a small fraction of overall LHA ${ }^{\text {GABA }}$ neurons (Fig. $1 A-F$ ). Importantly, LHA $^{G A B A}$ neurons heavily innervate the VTA (Nieh et al., 2015), while LHA ${ }^{\text {Gal }}$ neurons do not directly project to the VTA (Laque et al., 2015). Instead, LHA ${ }^{\text {Gal }}$ neurons heavily innervate LHA orexin neurons and the noradrendergic LC (Goforth et al., 2014; Laque et al., 2015). These results indicate that $\mathrm{LHA}^{\mathrm{Gal}}$ neurons represent a GABAergic subpopulation with a unique molecular identity and previous work also indicates a distinct projection profile that can be distinguished from the larger heterogeneous population of GABAergic neurons in the LHA.

\section{Chemogenetic activation of $\mathrm{LHA}^{\mathrm{Gal}}$ neurons enhances food-seeking behavior}

Recent data have highlighted the entire population of LHA ${ }^{G A B A}$ neurons as an important regulator of feeding behavior, emphasizing the $\mathrm{LHA}^{G A B A}$ projections to the VTA (LHA ${ }^{G A B A}>$ VTA projection) as particularly important in motivated feeding behaviors. Thus, here we tested whether activation of non-VTA projecting LHA $^{\text {Gal }}$ neurons would be sufficient to modulate sucrose-seeking behavior.

We first targeted DREADD-Gq or control virus into the LHA of $\mathrm{Gal}^{\mathrm{Cre}}$ mice (LHA $^{\text {Gal }}$ DREADD-Gq), which allowed us to selectively activate $\mathrm{LHA}^{\mathrm{Gal}}$ neurons with systemic CNO injections. Viral expression was visualized via the fluorescent marker mCherry to verify correct target-

ing throughout the LHA area (Fig. $2 A, B$ ). We verified neuronal stimulation capability of DREADD-Gq histologically with CNOinduced cFos expression in mCherry-positive neurons, which was prominent in the PFA (Fig. 2C, left) and extended through the LHA with some cFos-positive neurons in the zona incerta, while mice injected with control virus ( $\mathrm{LHA}^{\mathrm{Gal}} \mathrm{Control}$ ) showed little cFos in mCherry+ neurons (Fig. 2C, right).

E
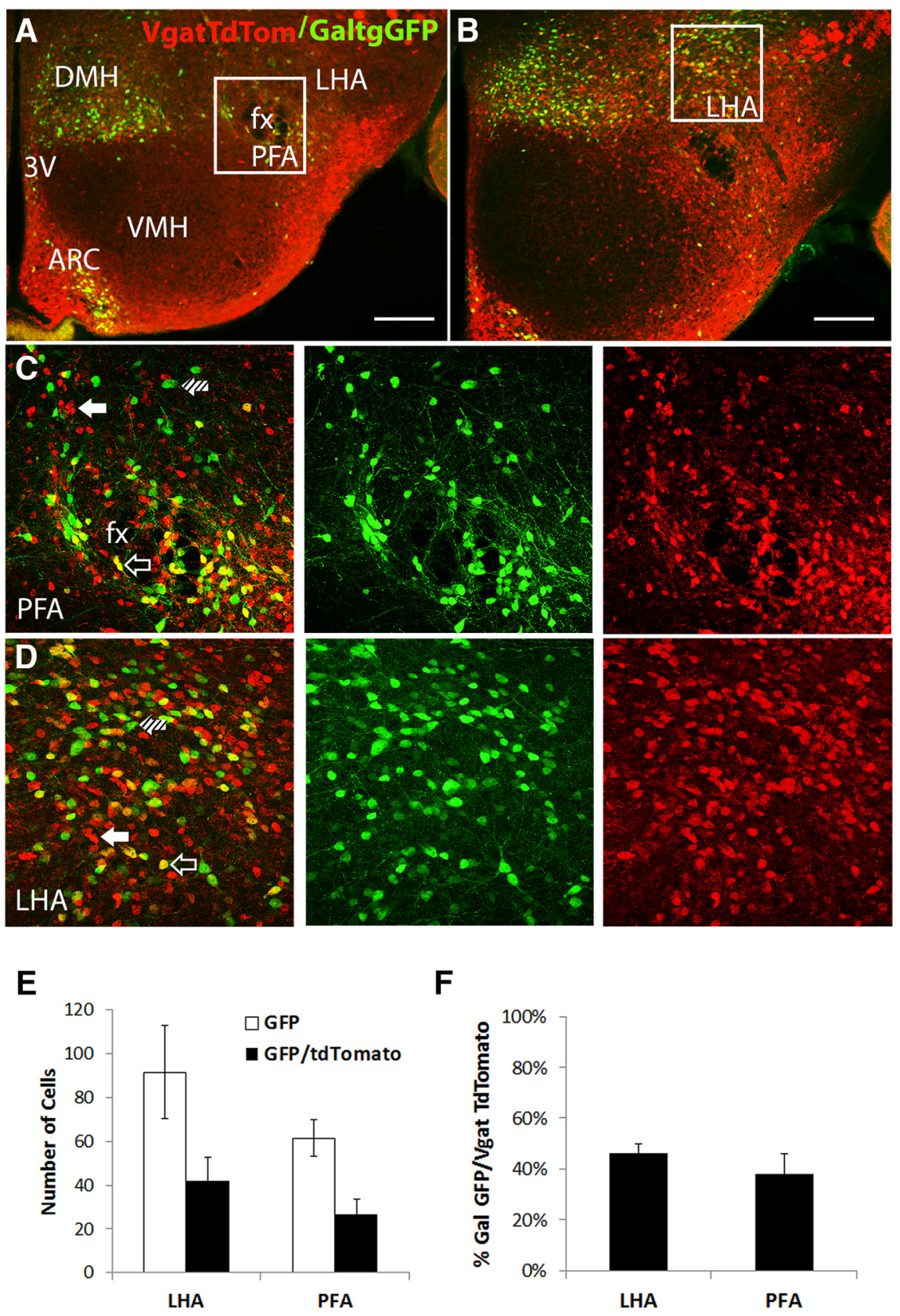

$\mathbf{F}$

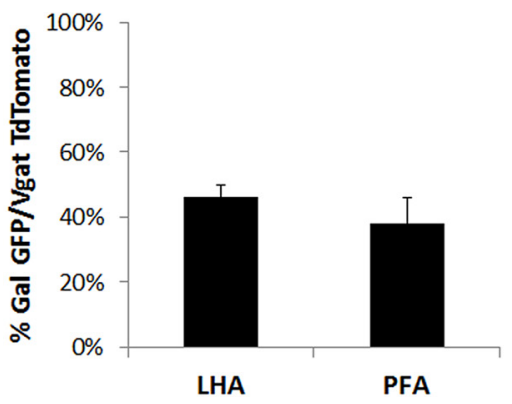

Figure 1. Galanin neurons in the LHA coexpress GABA. $A, B$, Overview of galanin-expressing (green) and Vgat-expressing (red) neurons in the hypothalamus of Gal ${ }^{\text {TgGFP }} /$ Vgat $^{T o m}$ mice (scale bar, $200 \mu \mathrm{m}$ ). C, D, Confocal image of the LHA depicting the PFA $(\boldsymbol{C})$ and the LHA dorsal of the PFA (D) in Gal ${ }^{\text {TgGFP }} /$ Vgat $^{\text {Tom }}$ mice. Sampled regions are indicated by white boxes in $\boldsymbol{A}$ and $\boldsymbol{B}$. Galanin-expressing neurons are shown in green (middle) and Vgat-expressing neurons are shown in red (right). The merged image (left) shows colocalization of galanin-expressing and Vgat-expressing neurons (yellow, open arrow), even though several nonVgat-expressing galanin neurons (green, striped arrow) and non-galanin-expressing Vgat neurons (red, filled arrow) were also present. $\boldsymbol{E}, \boldsymbol{F}$, Estimates of cell counts for total galanin ${ }^{\text {GFP }}$ neurons and double-labeled galanin ${ }^{\text {GFP }}$ /tdTomato neurons in the LHA and PFA of Gal ${ }^{\text {TgGFP }} /$ V gat $^{\text {Tom }}$ mice expressed as number of cells $(\boldsymbol{E})$ or as percentage of total galanin neurons $(\boldsymbol{F} ; n=4)$. Mean \pm SEM. 3V, Third ventricle; DMH, dorsomedial hypothalamus; ARC, arcuate nucleus; VMH, ventromedial hypothalamus; fx, fornix; PFA, perifornical area; LHA, lateral hypothalamic area; Vgat, vesicular GABA transporter; TdTom, TdTomato reporter gene; Gal, galanin; tgGFP, transgenic green fluorescence protein.

To quantify sucrose-seeking behavior, we trained the mice for operant responding with palatable sucrose pellets (Fig. 2D) and to perform increasing numbers of nose pokes to receive a sucrose pellet (PR testing). After stable PR performance, we activated LHA $^{\text {Gal }}$ neurons with systemic CNO injections $(1 \mathrm{mg} / \mathrm{kg})$ and compared their motivated behavior with PBS-injected mice. Activation of $\mathrm{LHA}^{\mathrm{Gal}}$ neurons significantly increased the total num- 
A AAV5-hSyn-DIO-hM3Dq-mCherry

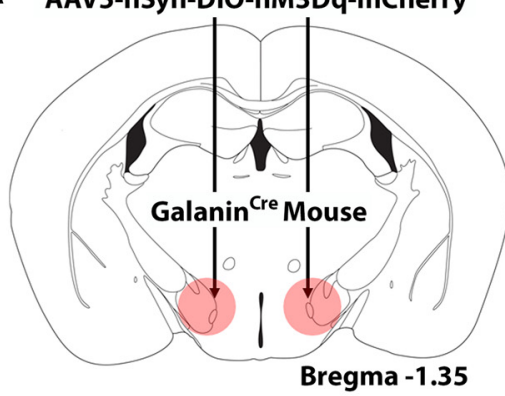

$\mathbf{B}$

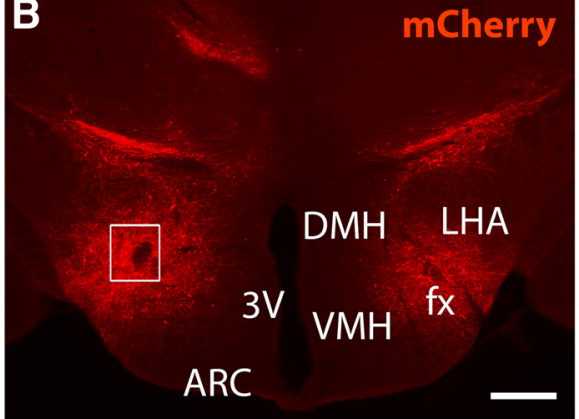

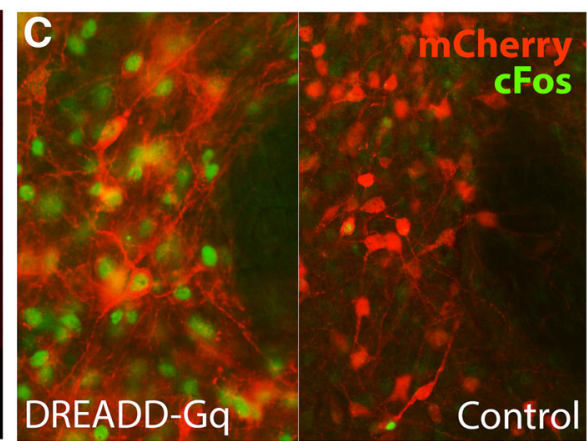

D

\begin{tabular}{|l|c|c|c|c|c|}
\hline Experimental Day & 1 & $2-8$ & $9-15$ & $16-22$ & $30+$ \\
\hline Operant Schedule & Autoshaping & FR1 & FR5 & PR-Train & PR-Test \\
\hline Feeding Schedule & \multicolumn{3}{|c|}{ Restricted } & Ad libitum \\
\hline
\end{tabular}

E
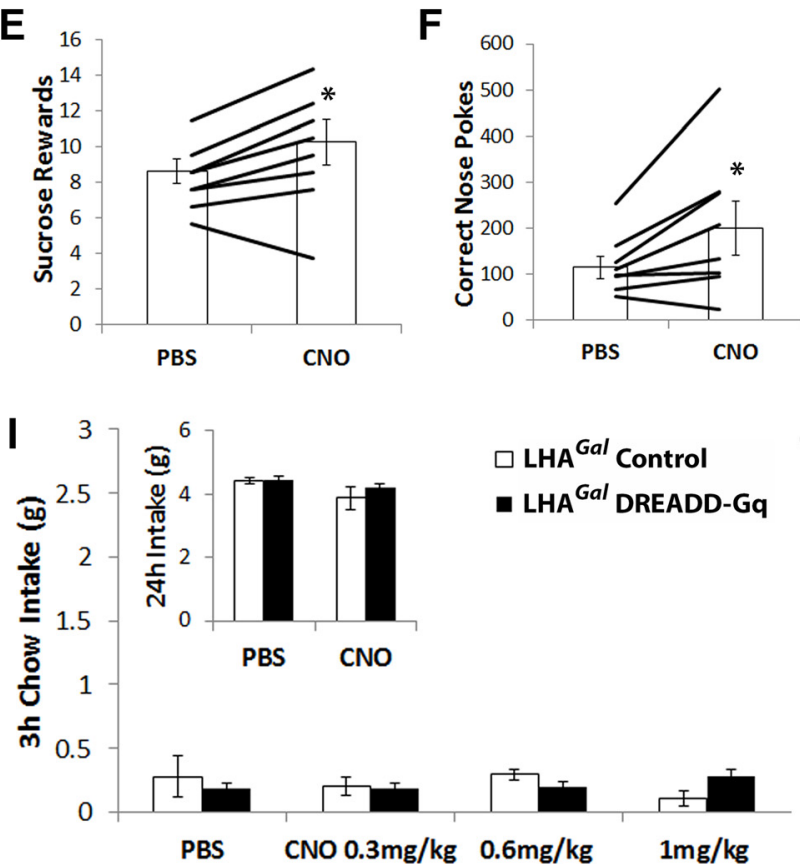

G

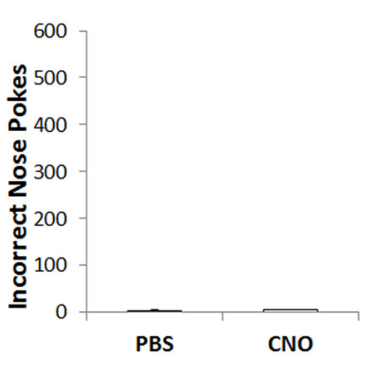

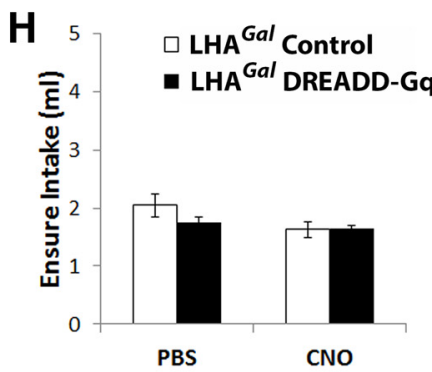

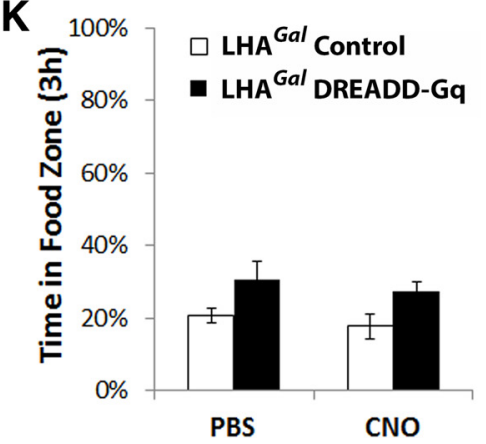

Figure 2. Activation of LHA ${ }^{G a l}$ neurons increases motivated feeding behavior. A, Illustration of viral injection sites to the LHA in Galanin ${ }^{\text {Cre }}$ mice with AAV5-hSyn-DI0-hM3Dq-mCherry (DREADD-Gq) or AAV5-hSyn-DI0-mCherry (control). B, Representative overview of hM3Dq-mCherry expression in the LHA of Galanin ${ }^{\text {Cre }}$ mice. $C$, Representative images of cFos (green) induction in $\mathrm{mCherry}$ (red) neurons following CNO (1 mg/kg) in LHA ${ }^{G a l}$ DREADD-Gq (left) and LHA ${ }^{G a l}$ Control (right) mice. D, Experimental procedure scheme for operant conditioning using fixed ratio (FR) and PR training. $\boldsymbol{E}-\boldsymbol{G}$, In the operant conditioning PR test, LHA ${ }^{\text {Gal }}$ DREADD-Gq mice injected with CNO $(1 \mathrm{mg} / \mathrm{kg}$, i.p.) significantly increases the total number of sucrose pellet rewards earned (E) and total number of correct nose pokes $(\boldsymbol{F})$, while the total number of incorrect nose pokes was unchanged $(\boldsymbol{G})$ compared with PBS-injected LHA ${ }^{G a l}$ DREADD-Gq mice. $\boldsymbol{H}$, Total $1 \mathrm{~h}$ intake of palatable fat solution (Ensure) was unchanged in CNO (1 mg/kg)-injected LHA ${ }^{\text {Gal }}$ DREADD-Gq or LHA ${ }^{\text {Gal }}$ Control mice. I, Acute (3 h) chow intake was unchanged in CNO (0.3-1 mg/kg, i.p.)-injected LHA ${ }^{\text {Gal }}$ DREADD-Gq or $\mathrm{LHA}^{\text {Gal }}$ Control mice. Also $24 \mathrm{~h}$ chow intake (inset; $1 \mathrm{mg} / \mathrm{kg}$ CNO) was unchanged. $J, \boldsymbol{K}$, In the food zone experiment $(\boldsymbol{J})$, we confirmed that CNO (1 mg/kg) had no effect on the time spent in the food zone during $3 \mathrm{~h}$ after injections $(\boldsymbol{K}) . \boldsymbol{E}-\boldsymbol{G},{ }^{*} p<0.05, n=8$, mean \pm SEM, paired $t$ test. $\boldsymbol{H}-\boldsymbol{K}, \mathrm{n}=4$ control, $n=9$ DREADD-Gq, two-way ANOVA or two-way repeated-measures ANOVA for dose-response experiments. 3V, Third ventricle; ME, median eminence; DMH, dorsomedial hypothalamus; ARC, arcuate nucleus; VMH, ventromedial hypothalamus; fx, fornix; LHA, lateral hypothalamic area; FR, fixed ratio; PR, progressive ratio; DREADD, Designer Receptors Exclusively Activated by Designer Drugs; W, water; F, food; Gal, galanin; PBS, phosphate-buffered saline; CNO, clozapine-N-oxide.

ber of sucrose rewards earned (Fig. 2E; paired $t$ test, $n=8, t_{(7)}=$ $-2.78, p<0.05)$ and the total number of correct nose pokes was likewise increased following $\mathrm{CNO}$ injections (Fig. 2F; paired $t$ test, $\left.n=8, t_{(7)}=-2.58, p<0.05\right)$. However incorrect nose pokes (no sucrose reward; Fig. $2 G$ ) were not changed, indicating a true increase of motivated behavior (sucrose seeking), rather than increased impulsive responding.

The operant driven PR task focuses on active food seeking and less on food consumption. To contrast food seeking with food consumption, we exposed animals to liquid Ensure (a palatable complete nutrition beverage) for $1 \mathrm{~h}$ over $5 \mathrm{~d}$. CNO or PBS injections were administered during the last $2 \mathrm{~d}$ in DREADD-Gqexpressing mice and mice that received a control virus injection. However, palatable food consumption remained unchanged by activation of LHA ${ }^{\text {Gal }}$ neurons (Fig. $2 H$ ). This suggests that activation of $\mathrm{LHA}^{\mathrm{Gal}}$ neurons specifically enhances the motivational aspect of food seeking rather than consumption of palatable food.

We further wanted to distinguish feeding of palatable food, which is mainly driven by a hedonic mechanism, from feeding of 
regular chow, which is mainly driven by homeostatic mechanisms. This was done in metabolic chambers to allow continuous $(24 \mathrm{~h})$ recording of food intake following CNO $(0.3-1 \mathrm{mg} / \mathrm{kg})$ and PBS injections in control and LHA ${ }^{\text {Gal }}$ DREADD-Gq mice. $\mathrm{CNO}$-induced activation of $\mathrm{LHA}^{\mathrm{Gal}}$ neurons did not change 3 or $24 \mathrm{~h}$ chow intake (Fig. 2I). We also measured the amount of time that the mice spent in proximity to the feeding container (Fig. $2 J$, Food Zone) over the $3 \mathrm{~h}$ following CNO or PBS injections, but the CNO did not affect the time spent in the food zone of the cage (Fig. 2K).

\section{Chemogenetic activation of $\mathrm{LHA}^{\mathrm{Gal}}$ neurons increases locomotor activity and energy expenditure}

LHA $^{G A B A}$ neurons have also been implicated in the regulation of arousal and wakefulness, and we therefore implanted mice with telemetric radio transmitters to assess the effect of galanin neuron stimulation on locomotor activity. Animals were implanted with telemetric radio transmitters for minute-by-minute measurement of locomotor activity. LHA ${ }^{\text {Gal }}$ DREADD-Gq and control mice were injected with PBS or CNO (1 mg/kg, i.p.). Indeed, CNO robustly induced locomotor activity that peaked at $1 \mathrm{~h}$ postinjection and returned to the baseline activity levels $\sim 3 \mathrm{~h}$ postinjection (Fig. 3A). Cumulative locomotor activity (over the first $3 \mathrm{~h}$ postinjection) showed a significant 2.5 -fold increase in locomotor activity in CNO-injected LHA ${ }^{\text {Gal }}$ DREADD-Gq mice, but not in control mice (Fig. 3B; LHA ${ }^{\text {Gal }}$ Control, $n=4$; LHA ${ }^{\text {Gal }}$ DREADD-Gq, $n=9$; ANOVA for the interaction between treatment and group: $\left.F_{(1,22)}=5.071, p<0.05\right)$.

We also measured locomotor activity by beam breaks in the TSE System, which measures 3D movements including up-and-down rearing, in contrast to the telemetric measurements that exclusively captures 2D movements in the cage. We confirmed an increase in locomotor activity following $\mathrm{CNO}$ injection, which returned to PBS baseline levels at $3 \mathrm{~h}$ postinjection (Fig. $3 \mathrm{C}$; $n=4 \mathrm{LHA}^{\text {Gal }}$ Control; $n=9 \mathrm{LHA}^{\text {Gal }}$ DREADD-Gq; repeated-measures ANOVA for the interaction between group and interval, $\left.F_{(7,77)}=6.494 ; p<0.001\right)$. Comparing cumulative locomotor activity we found a doubling of locomotor activity in LHA ${ }^{G a l}$ DREADD-Gq mice at all tested CNO doses compared with control mice (Fig. 3D; repeated-measures ANOVA for the interaction between group and level of drug, $\left.F_{(3,33)}=4.584 ; p<0.01\right)$.

We further analyzed $\mathrm{VO}_{2}$ consumption in these mice as locomotor activity drives $\mathrm{VO}_{2}$ consumption as a measure for energy expenditure. $\mathrm{CNO}$ consistently increased $\mathrm{VO}_{2}$ mildly compared with PBS-treated mice (Fig. $3 E, F$ ), but only reached significance at a CNO dose of $1 \mathrm{mg} / \mathrm{kg}$ (Fig. $3 F$; repeated-measures ANOVA for the interaction between group and level of drug, $F_{(3,33)}=$ $4.413, p<0.01)$. This further suggests that increased locomotor activity may also induce locomotion with less effect on oxygen consumption (e.g., head movements).

Thus, activation of LHA $^{\text {Gal }}$ neurons showed a clear increase in locomotor activity that is in line with increased wakefulness during the light cycle, where nocturnal mice are typically asleep. Indeed, while CNO-injected LHA ${ }^{G a l}$ DREADD-Gq animals were awake and engaged in various behaviors, control or PBS-injected animals were often asleep. Notably, activation of $\mathrm{LHA}^{\mathrm{Gal}}$ neurons did not induce compulsive-like behavior, in contrast to the compulsive eating or foraging locomotor behavior induced by activation of LHA ${ }^{\text {GABA }}$ neurons as reported by others (Jennings et al., 2015; Venner et al., 2016).

\section{Chemogenetic activation of LHA ${ }^{G A B A}$ neurons increases food-seeking and food-consumption behavior}

To allow a more precise comparison of LHA ${ }^{G A B A}$ neurons to LHA $^{\text {Gal }}$ neurons, we performed chemogenetic activation of LHA $^{G A B A}$ neurons using the exact experimental setup as used for chemogenetic activation of $\mathrm{LHA}^{\mathrm{Gal}}$ neurons.

LHA $^{\text {GABA }}$ neurons were targeted by viral injections into $\mathrm{Vgat} \mathrm{C}^{\mathrm{Cre}}$ mice (Vong et al., 2011) using the same stereotaxic coordinates as described for $\mathrm{Gal}^{\mathrm{Cre}}$ mice, with correct viral targeting to the LHA validated histochemically (Fig. $4 A-C$ ). Functional validation was confirmed by comparing CNO-induced cFos in mCherry + neurons in LHA ${ }^{\text {Vgat }}$ DREADD-Gq mice with LHA ${ }^{\text {Vgat }}$ Control animals. Only LHA $^{\text {Vgat }}$ DREADD-Gq mice showed robust CNO-induced cFos in mCherry + neurons, while CNO-injected control mice showed only few cFos+ neurons (Fig. 4B, C).

Food-seeking behavior in LHA ${ }^{\text {Vgat }}$ DREADD-Gq mice was examined using the same operant conditioning schedule as for $\mathrm{Gal}^{\mathrm{Cre}}$ mice (Fig. 2D). Initially, when testing operant responding with a $\mathrm{CNO}$ dose of $1 \mathrm{mg} / \mathrm{kg}$, all mice exhibited an erratic, compulsive-like locomotor behavior (see below) and failed to perform any significant number of nose pokes (data not shown). In an effort to moderate this compulsive-like locomotor behavior, we tested all animals with decreasing $\mathrm{CNO}$ doses and measured PR responding for all animals. In seven of eight mice, we found a $\mathrm{CNO}$ dose that increased operant responding. However, the CNO dose sufficient to enhance operant responding and low enough to moderate compulsive locomotor activity was highly variable, possibly due to minute differences in viral expression levels and anatomical locations. To visualize CNOinduced operant behavior, we plotted the maximal CNOinduced operant response for each animal in Figure $4 D, E$. Note that the individual data in Figure $4 D, E$ were induced by varying CNO doses. For clarity, we have color-coded the individual response data for the used $\mathrm{CNO}$ dose in the figure legend. With this analysis we confirm earlier reports (Jennings et al., 2015) and show that activation of LHA ${ }^{G A B A}$ neurons increased total number of sucrose rewards earned (Fig. $4 E$; paired $t$ test, $\left.n=8, t_{(7)}=-2.73, p<0.05\right)$ and correct nose pokes (Fig. $4 E$; paired $t$ test, $n=8, t_{(7)}=-2.75, p<0.05$ ), but did not alter the number of incorrect nose pokes (not leading to sucrose pellet; Fig. $4 F$ ). Neither $\mathrm{CNO}$ dose induced incorrect nose pokes, indicating that the erratic behavior did not induce impulsive responding but rather prevented the animals from engaging in the learned task at all.

Activation of LHA ${ }^{G A B A}$ neurons did not change hedonic food consumption in a paradigm with $1 \mathrm{~h}$ access to liquid Ensure (Fig. $4 G$ ), but chow consumption over $3 \mathrm{~h}$ but not $24 \mathrm{~h}$ was increased by CNO (Fig. $4 H ; n=4 \mathrm{LHA}^{\text {Vgat }}$ Control; $n=8 \mathrm{LHA}^{\text {Vgat }}$ DREADD-Gq, for $0.1 \mathrm{mg} / \mathrm{kg}$ CNO: $U_{(3,7)}=3.0, T=13.0, p<$ 0.05; for $0.3 \mathrm{mg} / \mathrm{kg}$ CNO: $U_{(3,7)}=4.0, T=14.0, p<0.05 ; 3 \mathrm{~h}$ chow intake at $1 \mathrm{mg}$ failed to reach significance: $U_{(3,7)}=6.0, T=$ $16.0, p=0.10)$. Note, that these data were generated using decreasing doses of CNO (0.1-1 mg/kg, i.p.) as used for LHA ${ }^{\text {Gal }}$ neuronal activation, again to moderate compulsive locomotor behavior. There was high variability among individual mice in this experiment, with several of the mice demonstrating more robust increases in food intake during the $3 \mathrm{~h}$ period following $\mathrm{CNO}$ injection. Despite the increase in food intake, there was no increase in time spent in the food zone during the $3 \mathrm{~h}$ following CNO injection for the LHA ${ }^{\text {Vgat }}$ DREADD-Gq mice (Fig. 4I). 
A

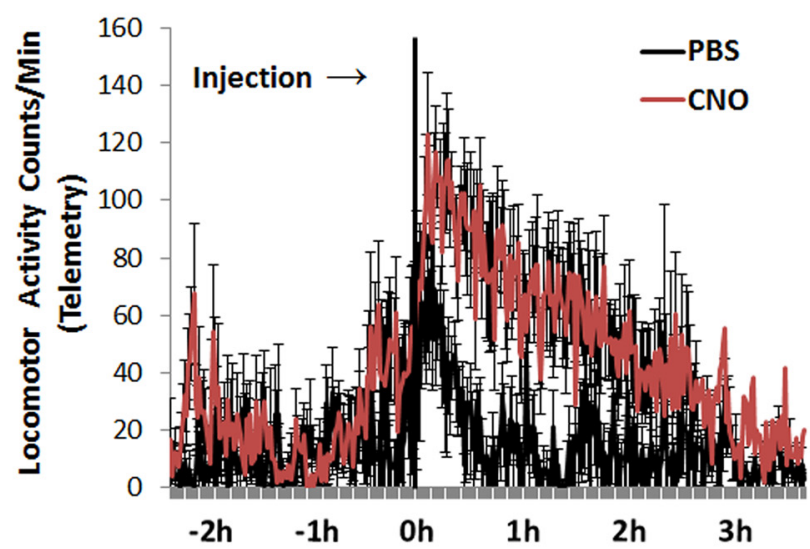

B

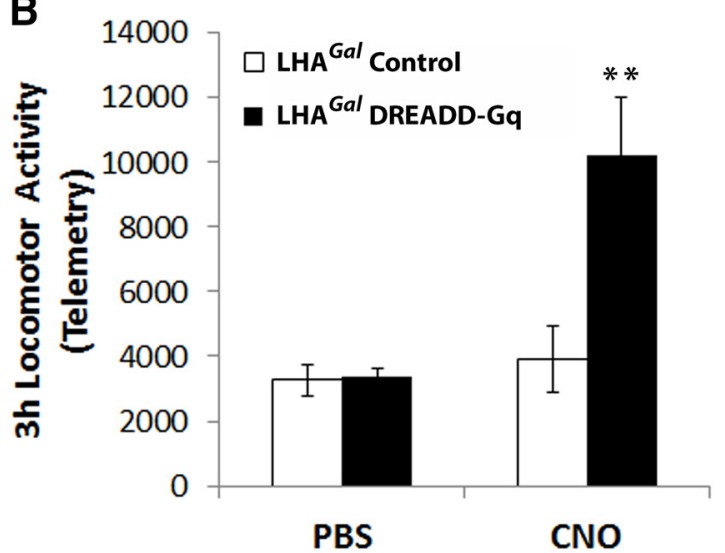

D

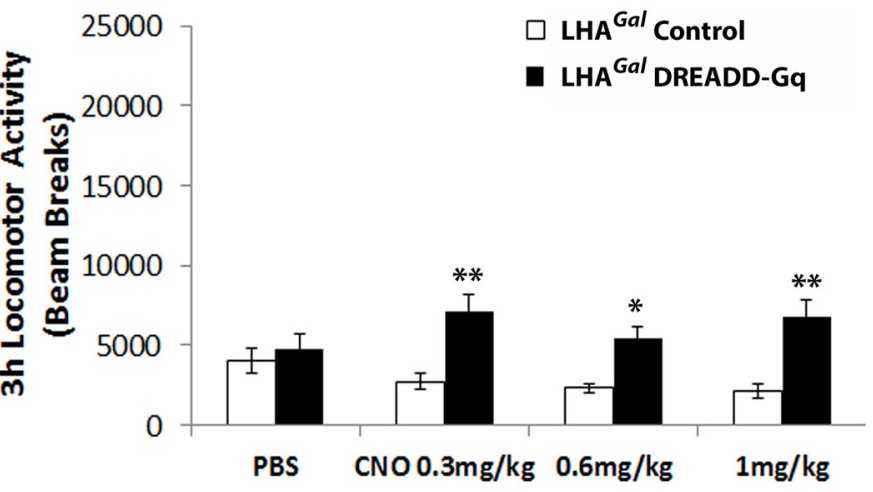

$\mathbf{F}$

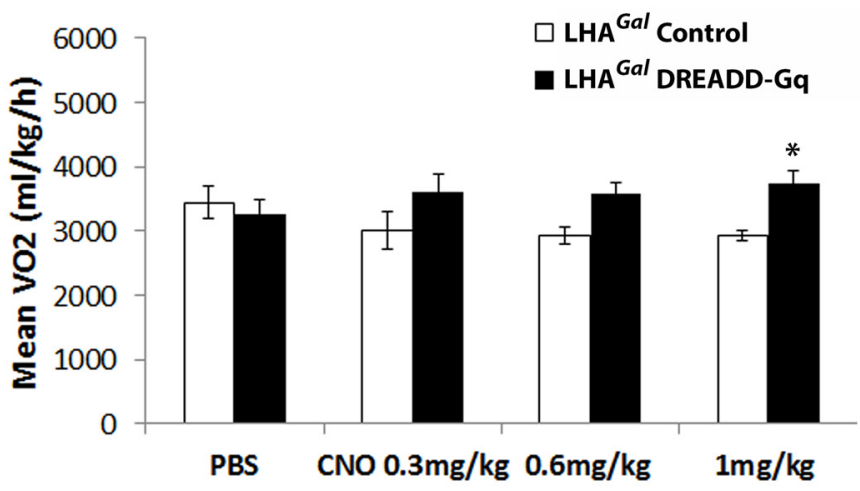

Figure 3. Activation of $\mathrm{LHA} \mathrm{A}^{\text {Gal }}$ neurons increases locomotor activity. $A$, Locomotor activity before and after injection of PBS or CNO (1 mg/kg) in LHA ${ }^{\text {Gal }}$ DREADD-Gq mice $(n=9)$ as measured by telemetry in 1 min increments. B, Cumulative locomotor activity ( $3 \mathrm{~h}$ postinjection, measured by telemetry) was significantly increased following CNO (1 mg/kg) injection in LHA ${ }^{\text {Gal }}$ DREADD-Gq mice $(n=9)$, but not in LHA ${ }^{G a l}$ Control mice ( $n=4$; 2-way ANOVA, pairwise comparisons by Holm-Sidak method). C, Locomotor activity as measured by beam breaks was increased in LHA ${ }^{G a l}$ DREADD-Gq mice following CNO (1 mg/kg) injection compared with LHA ${ }^{\text {Gal }}$ Controls. D, Different CNO doses (0.3-1 mg/kg, i.p.) were tested for CNO-induced locomotor activity measured by beam breaks and no reduction in behavioral effects was observed with the tested doses. $E, F, 0 x y g$ en consumption measurement in metabolic chambers showed only mild effects of $C \mathrm{CNO}(1 \mathrm{mg} / \mathrm{kg})$-induced locomotor activity on energy expenditure $(\boldsymbol{E})$, which was significant only at the highest CNO dose tested $(1 \mathrm{mg} / \mathrm{kg} ; \boldsymbol{F}) . \boldsymbol{C}-\boldsymbol{F}, \mathrm{n}=4 \mathrm{LHA}{ }^{\text {Gal }}$ Control; $n=9$ LHA ${ }^{\text {Gal }}$ DREADD-Gq, two-way repeated-measures ANOVA, pairwise comparisons by Holm-Sidak method. All data are represented as mean $\pm \mathrm{SEM},{ }^{*} p<0.05,{ }^{* *} p<0.01$, and ${ }^{* * *} p<0.001$. LHA, lateral hypothalamic area; DREADD, Designer Receptors Exclusively Activated by Designer Drugs; Gal, galanin; PBS, phosphate-buffered saline; CNO, clozapine-N-oxide.

Chemogenetic activation of LHA ${ }^{\text {GABA }}$ neurons increases locomotor activity more robustly than activation of $\mathrm{LHA}^{\mathrm{Gal}}$ neurons

We further measured locomotor activity following CNO injection in LHA ${ }^{\text {Vgat }}$ DREADD-Gq and LHA ${ }^{\text {Vgat }}$ Control mice using telemetry in their home cages and beam breaks in metabolic chambers. We found both measures showed a strong increase in locomotor activity, which continued to be elevated for $\sim 6 \mathrm{~h}$ following injection. Using telemetric monitoring of locomotor activity, LHA ${ }^{\text {Vgat }}$ DREADD-Gq and LHA ${ }^{\text {Vgat }}$ Control mice were injected with PBS or CNO (0.1 mg/kg, i.p.). We observed a CNOinduced increase in locomotor activity that peaked at $1 \mathrm{~h}$ postinjection and this increase continued until $5 \mathrm{~h}$ postinjection before 

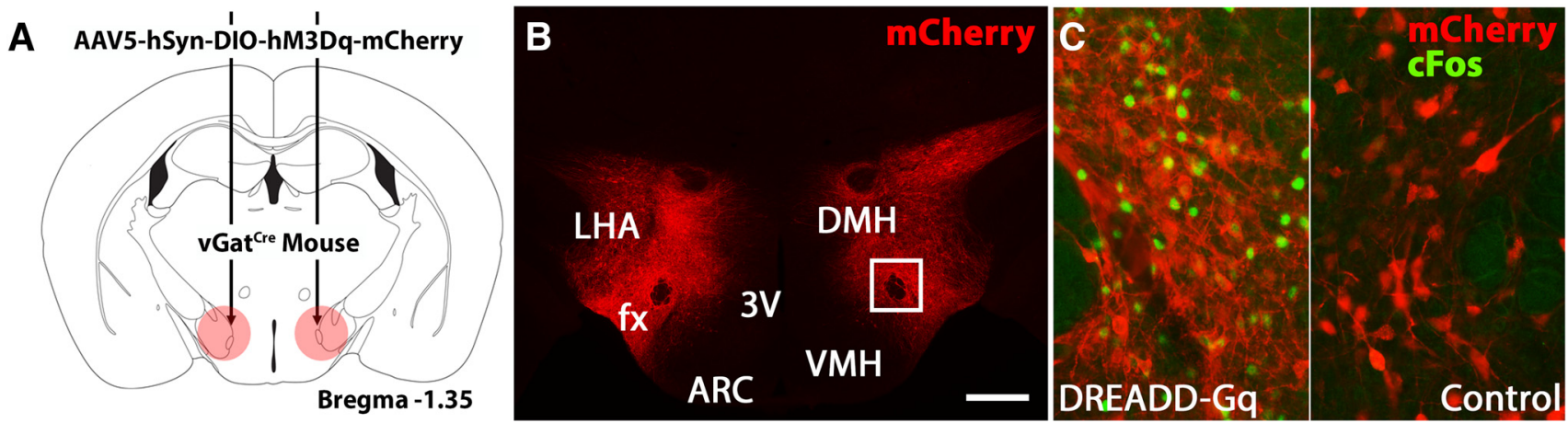

D
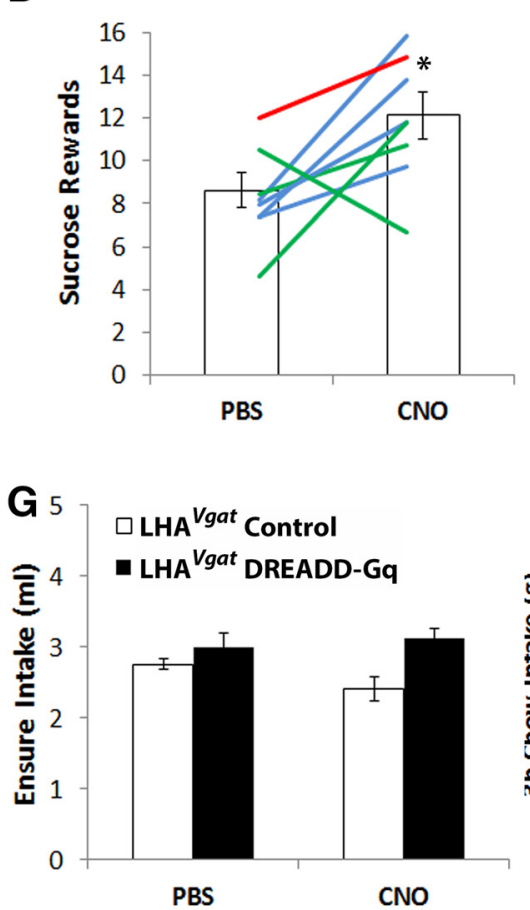

$\mathbf{E}$

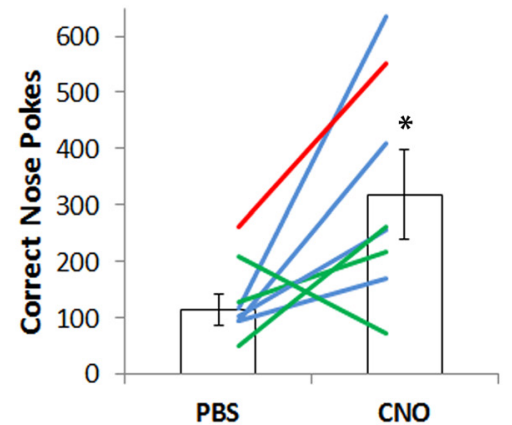

$\mathbf{F}$

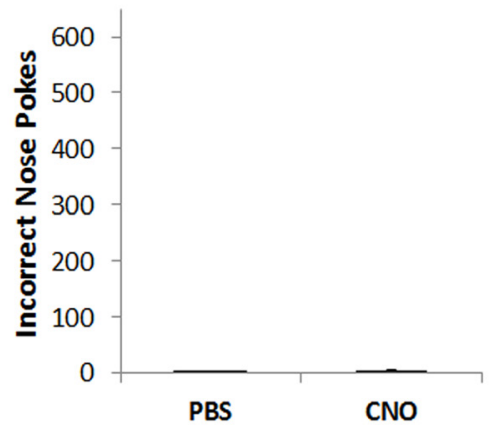

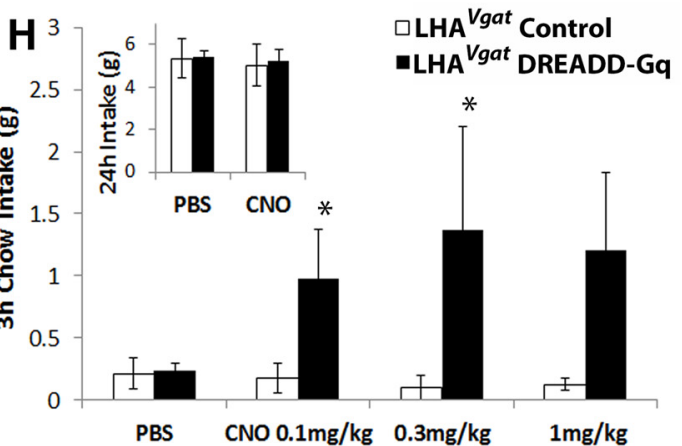

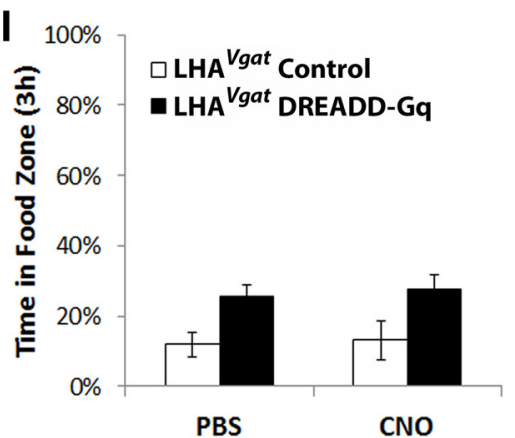

Figure 4. Activation of $L H A A^{G A B A}$ neurons increases motivated feeding and chow intake. A, Illustration of viral injection sites to the LHA in Vgat ${ }^{\text {(re }}$ mice with AAV5-hSyn-DI0-hM3Dq-mCherry (DREADD-Gq) or AAV5-hSyn-DI0-mCherry (control). B, Representative overview of hM3Dq-mCherry expression in the LHA of Vgat ${ }^{\text {Cre }}$ mice. C, Representative images of cFos (green) induction in $\mathrm{mCherry} \mathrm{(red)} \mathrm{neurons} \mathrm{following} \mathrm{CNO} \mathrm{(1} \mathrm{mg/kg)} \mathrm{in} \mathrm{DREADD-Gq} \mathrm{(left)} \mathrm{and} \mathrm{control} \mathrm{(right)} \mathrm{injected} \mathrm{Vgat}{ }^{\text {Cre }}$ mice. D-F, In the operant conditioning PR test, LHA ${ }^{\text {Vat }}$ DREADD-Gq mice injected with CNO $(0.05-0.2 \mathrm{mg} / \mathrm{kg}$, i.p.) significantly increases the total number of sucrose pellet rewards earned $(\boldsymbol{D})$ and total number of correct nose pokes (E; CNO dose-response experiment was performed and data are presented as maximal effective CNO dose per individual; green line, $0.05 \mathrm{mg} / \mathrm{kg}$; blue, $0.1 \mathrm{mg} / \mathrm{kg}$; red, $0.2 \mathrm{mg} / \mathrm{kg}$ ), while the total number of incorrect nose pokes was unchanged (F) compared with PBS-injected LHA ${ }^{\text {Vgat }}$ DREADD-Gq mice. G, Total $1 \mathrm{~h}$ intake of palatable fat solution (Ensure) was unchanged in CNO (0.1 mg/kg)-injected LHA ${ }^{\text {Vgat }}$ DREADD-Gq or LHA ${ }^{\text {Vgat }}$ Control mice. $\boldsymbol{H}$, Acute $(3 \mathrm{~h})$ chow intake was increased in CNO $\left(0.1\right.$ and $0.3 \mathrm{mg} / \mathrm{kg}$, i.p.)-injected LHA ${ }^{\text {Vgat }}$ DREADD-Gq compared with LHA ${ }^{\text {Vgat }}$ Control mice and PBS-injected LHA ${ }^{\text {Vgat }}$ DREADD-Gq mice. However, $24 \mathrm{~h}$ chow intake (inset; $0.1 \mathrm{mg} / \mathrm{kg}$ CNO) was unchanged. $I$ I In the food zone experiment, we confirmed that CNO $(0.1 \mathrm{mg} / \mathrm{kg}$ ) had no effect on the time spent in the food zone during $3 \mathrm{~h}$ postinjection (K). $\boldsymbol{D}-\boldsymbol{F}_{,}{ }^{*} p<0.05, n=8$, mean \pm SEM, paired $t$ test. $\mathbf{G}-\mathbf{I}, \mathrm{n}=4 \mathrm{LHA}^{\text {Vgat }}$ Control; $n=8 \mathrm{LHA}{ }^{\text {Vgat }}$ DREADD-Gq; two-way ANOVA or Mann-Whitney rank sum test for dose-response experiments. 3V, Third ventricle; ME, median eminence; DMH, dorsomedial hypothalamus; ARC, arcuate nucleus; VMH, ventromedial hypothalamus; fx, fornix; LHA, lateral hypothalamic area; DREADD, Designer Receptors Exclusively Activated by Designer Drugs; Gal, galanin; PBS, phosphate-buffered saline; CNO, clozapine-N-oxide.

returning to the baseline activity levels (Fig. 5A). Cumulative locomotor activity (over the first $3 \mathrm{~h}$ postinjection) was measured during the $3 \mathrm{~h}$ following CNO or PBS injection showing a significant 2.5-fold increase in locomotor activity in LHA ${ }^{\text {Vgat }}$ DREADD-Gq mice, but not in LHA ${ }^{\text {Vgat }}$ Control mice (Fig. $5 B$; LHA $^{\text {Vgat }}$ Control, $n=4$; LHA $^{\text {Vgat }}$ DREADD-Gq, $n=8$; ANOVA for the interaction between treatment and group: $F_{(1,20)}=$ $18.663, p<0.001)$. These data were similar to data for locomotor activation of LHA ${ }^{\text {Gal }}$ neurons. In contrast, locomotor activity measured by beam breaks (adding up-and-down movements like rearing) in the TSE System reflected a stronger locomotor behavior after LHA ${ }^{G A B A}$ neuron activation compared with activation of LHA ${ }^{\text {Gal }}$ neurons. Locomotor activity increased quickly following $\mathrm{CNO}$ in- jection and returned to PBS baseline levels at $6 \mathrm{~h}$ postinjection (Fig. 5C; LHA $^{\text {Vgat }}$ Control, $n=4$; LHA ${ }^{\text {Vgat }}$ DREADD-Gq, $n=8$; repeated-measures ANOVA for the interaction between group and interval, $\left.F_{(8,80)}=2.771 ; p<0.01\right)$. Comparing cumulative increases (sum of beam breaks during $3 \mathrm{~h}$ following injection) in locomotor activity, $\mathrm{LHA}^{\mathrm{GABA}}$ neuronal activation caused a fourfold increase in locomotor activity at multiple CNO dosages (Fig. $5 D$; LHA $^{\text {Vgat }}$ Control, $n=4$; LHA ${ }^{\text {Vgat }}$ DREADD-Gq, $n=8$; repeated-measures ANOVA for the interaction between group and level of drug, $\left.F_{(3,47)}=8.389 ; p<0.001\right)$, in contrast to the twofold induction after LHA ${ }^{\text {Gal }}$ neuron activation (Fig. 3D).

Energy expenditure $\left(\mathrm{VO}_{2}\right)$ also increased with activation of $\mathrm{LHA}^{\mathrm{GABA}}$ neurons, which extended $\sim 4 \mathrm{~h}$ following CNO injection 
A

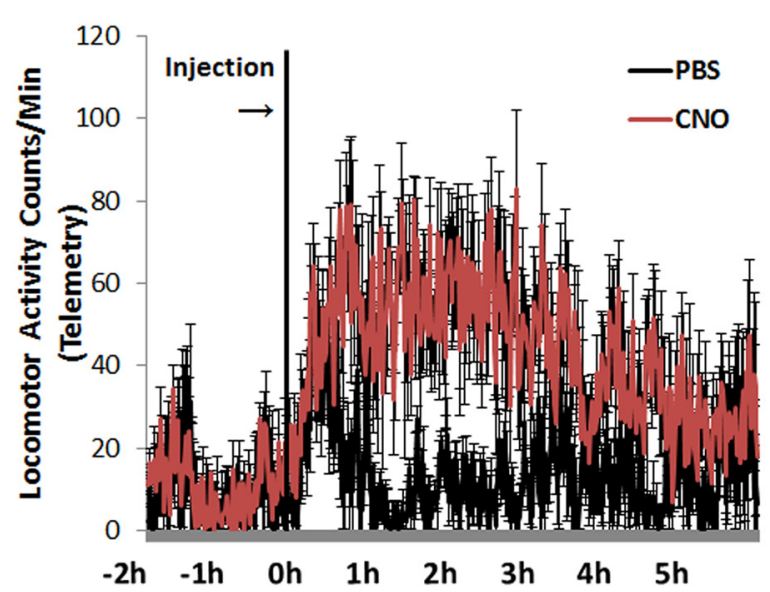

B

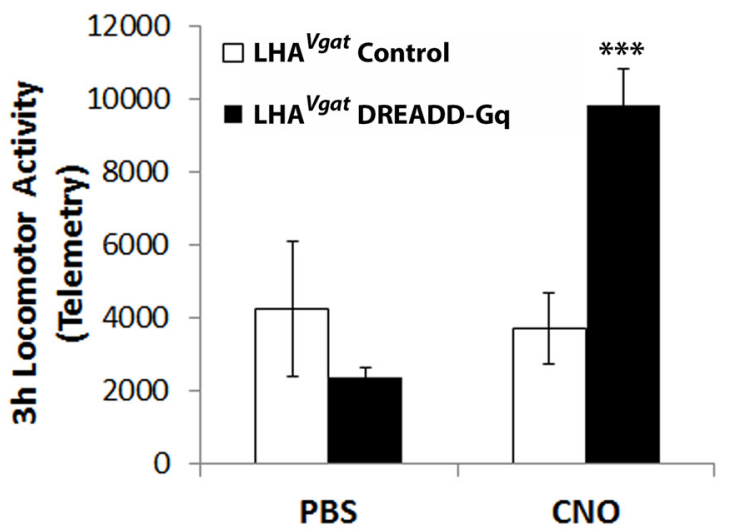

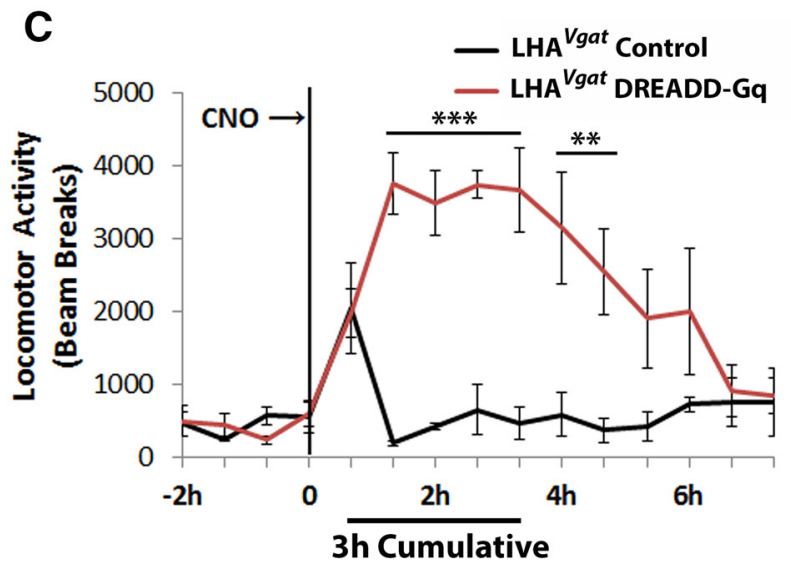

D

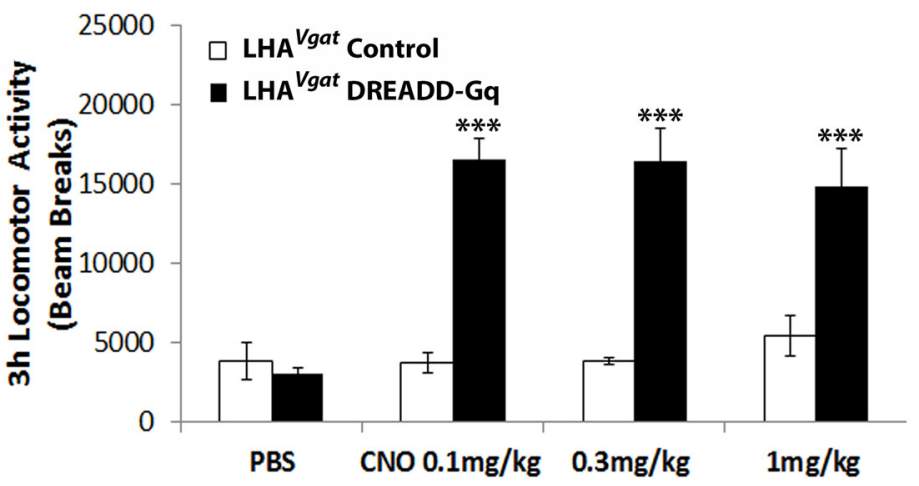

$\mathbf{E}$

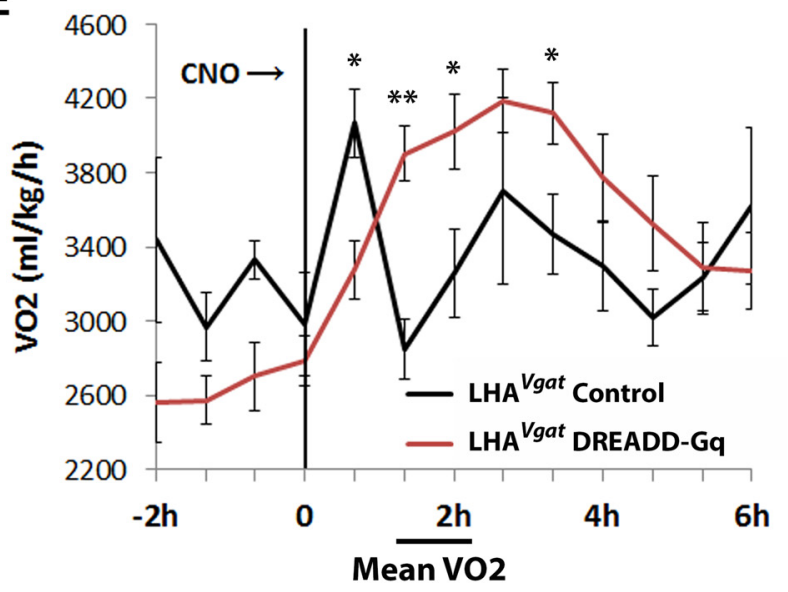

$\mathbf{F}$

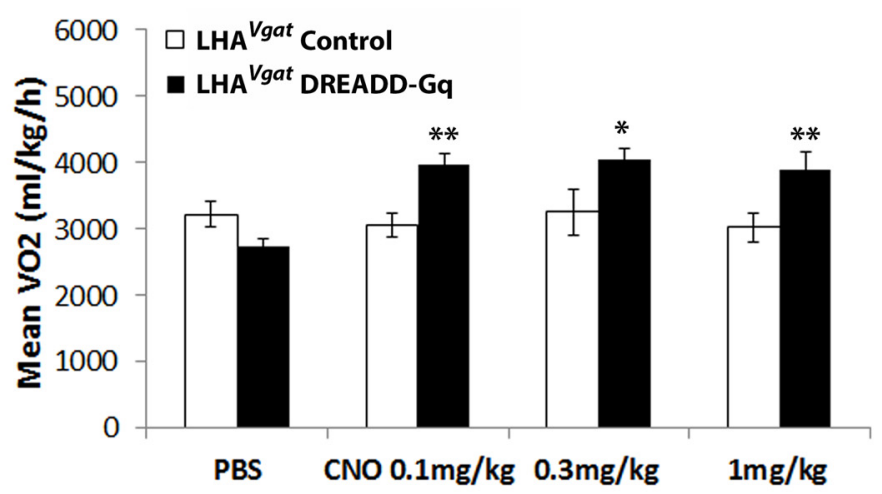

Figure 5. Activation of $L H A A^{G A B A}$ neurons robustly increases locomotor activity. $A$, Locomotor activity before and after injection of PBS or CNO (1 mg/kg) in LHA ${ }^{V a a t}$ DREADD-Gq mice $(n=8)$ as measured by telemetry in 1 min increments. B, Cumulative locomotor activity ( $3 \mathrm{~h}$ postinjection, measured by telemetry) was significantly increased following CNO (0.1 mg/kg) injection in LHA $A^{\text {Vgat }}$ DREADD-Gq mice $(n=8)$, but not in LHA ${ }^{\text {Vgat }}$ Control mice ( $n=4 ; 2$-way ANOVA, pairwise comparisons by Holm-Sidak method). C, Locomotor activity as measured by beam breaks was increased in LHA ${ }^{\text {Vgat }}$ DREADD-Gq mice following CNO (1 mg/kg) injection compared with LHA ${ }^{\text {Vgat }}$ Controls. D, Different CNO doses $(0.1-1 \mathrm{mg} / \mathrm{kg}$, i.p.) were tested for CNO-induced locomotor activity measured by beam breaks and no reduction in behavioral effects was observed with the tested doses. $E, F, 0 x y g e n$ consumption measurement in metabolic chambers showed significant effects of CNO (0.1 $\mathrm{mg} / \mathrm{kg}$ )-induced locomotor activity on energy expenditure $(\boldsymbol{E})$, which was significant at all CNO doses tested $(0.1-1 \mathrm{mg} / \mathrm{kg} ; \boldsymbol{F})$. $\boldsymbol{C}-\boldsymbol{F}, n=4 \mathrm{LHA}^{\text {Vgat }}$ Control; $n=8$ LHA ${ }^{\text {Vgat }}$ DREADD-Gq; two-way repeated-measures ANOVA, pairwise comparisons by Holm-Sidak method. All data are represented as mean $\pm \mathrm{SEM},{ }^{*} p<0.05,{ }^{* *} p<0.01$, and ${ }^{* * *} p<0.001$. LHA, lateral hypothalamic area; DREADD, Designer Receptors Exclusively Activated by Designer Drugs; Gal, galanin; PBS, phosphate-buffered saline; CN0, clozapine-N-oxide.

(Fig. 5E; LHA ${ }^{\text {Vgat }}$ Control, $n=4$; LHA ${ }^{\text {Vgat }}$ DREADD-Gq, $n=8$; repeated-measures ANOVA for the interaction between group and interval, $\left.F_{(8,80)}=4.428 ; p<0.001\right)$. Mean $\mathrm{VO}_{2}$ was likewise increased following CNO injection at each dosage of drug tested (0.1-1 $\mathrm{mg} / \mathrm{kg}$; Fig. 5F; LHA ${ }^{\text {Vgat }}$ Control, $n=4$; LHA ${ }^{\text {Vgat }}$ DREADD-Gq, $n=$
8; repeated-measures ANOVA for the interaction between group and level of drug, $\left.F_{(3,30)}=12.026, p<0.001\right)$. LHA ${ }^{G A B A}$ neuronal activation induced a stronger and more prolonged effect on locomotor activity and $\mathrm{VO}_{2}$ than did activation of LHA ${ }^{\text {Gal }}$ neurons, suggesting that galanin neurons in the LHA represent a molecularly distinct 
A
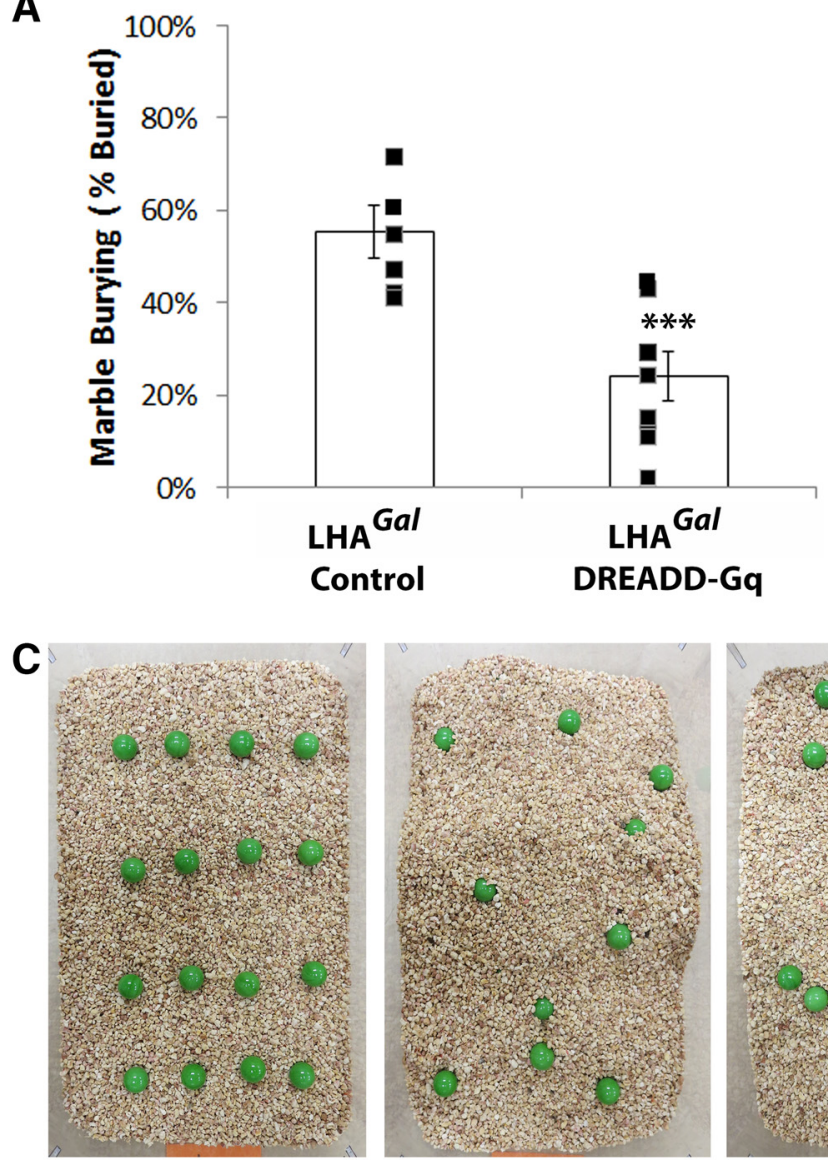

Start
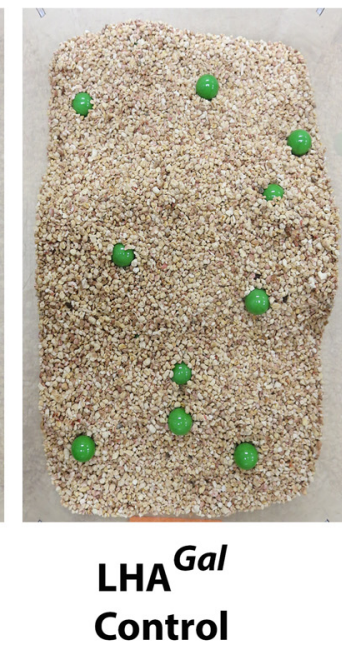

B

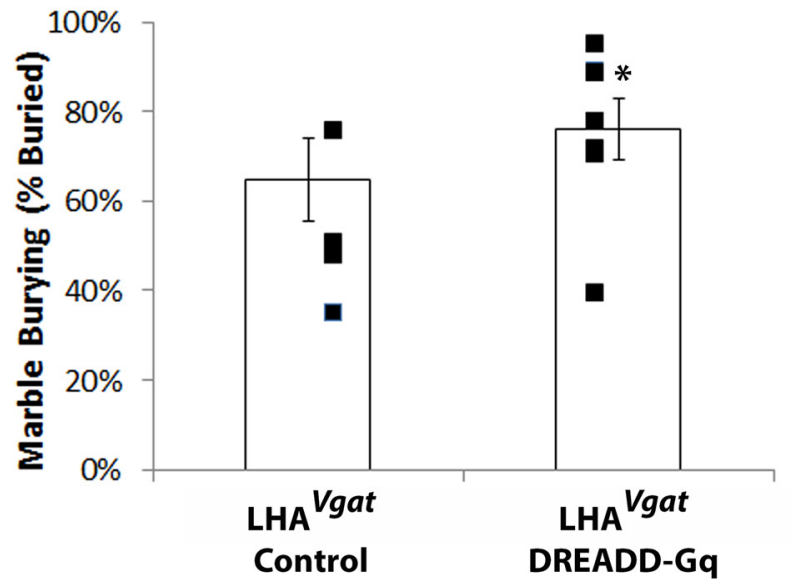

Figure 6. Activation of $\mathrm{LHA}{ }^{\text {Gal }}$ neurons reduces compulsive burying. In contrast, LHA ${ }^{G A B A}$ activation increases burying. $A$, Marble-burying behavior following CNO injection (1 mg/kg) in LHA ${ }^{\text {Gal }}$ DREADD-Gq mice $(n=9)$ is decreased compared with LHA ${ }^{\text {Gal }}$ Control mice $(n=6)$. $\boldsymbol{B}$, Marble-burying behavior following CN0 injection (0.1 mg/kg) LHA ${ }^{\text {Vgat }}$ DREADD-Gq mice $(n=8)$ is increased compared with LHA ${ }^{\text {Vgat }}$ Control mice $(n=4)$. All data are represented as mean $\pm \mathrm{SEM}$, paired $t$ test, ${ }^{*} p<0.05,{ }^{* * *} p<0.001$. C, Representative images of marble placement at test start (far left), and at the end of 30 min testing period for LHA ${ }^{\text {Gal }}$ control (left), LHA ${ }^{\text {Gal }}$ DREADD-Gq (middle), LHA ${ }^{\text {Vgat }}$ control (right), and LHA ${ }^{\text {Vgat }}$ DREADD-Gq (far right). LHA, lateral hypothalamic area; DREADD, Designer Receptors Exclusively Activated by Designer Drugs; Gal, galanin.

subset of the overall GABA population in the LHA. It may also suggest a role for a different transmitter system that coexpresses with $\mathrm{GABA}$, but is distinct from galanin neurons.

\section{LHA ${ }^{G A B A}$ neurons, but not LHA ${ }^{\text {Gal }}$ neurons, induce} compulsive-like behavior

LHA $^{\text {Vgat }}$ DREADD-Gq mice showed CNO-induced hyperactive compulsive-like behavior (i.e., digging in bedding, gnawing on inedible objects in the cage), and was clearly distinct from CNOinduced locomotor activity in LHA ${ }^{\text {Gal }}$ DREADD-Gq mice. To further examine the nature of the hyperactive behavior following LHA $^{G A B A}$ neuronal activation, we used the marble-burying test. The marble-burying test is a measure of stereotypical behavior and is accepted as an indicator of psychiatric conditions, such as anxiety and obsessive-compulsive disorder. Rodent behavior in the marble-burying test can be manipulated with common pharmacological modulators of these conditions, such as anxiolytics and 5-HT compounds (Deacon, 2006; Angoa-Perez et al., 2013). LHA $^{\text {Gal }}$ DREADD-Gq and LHA ${ }^{\text {Vgat }}$ DREADD-Gq mice demonstrated a striking difference in $\mathrm{CNO}$-induced marble-burying behavior. Compared with control mice, activation of LHA ${ }^{\text {Gal }}$ neurons (CNO dose: $1 \mathrm{mg} / \mathrm{kg}$ ) resulted in significantly fewer bur- ied marbles (Fig. 6A, $C$; $n=6$ LHA $^{\text {Gal }}$ Control; $n=9$ LHA $^{\text {Gal }}$ DREADD-Gq; $T_{(13)}=4.126, p<0.001$ ), while activation of LHA $^{\text {GABA }}$ neurons (CNO dose $0.1 \mathrm{mg} / \mathrm{kg}$ ) resulted in significantly more buried marbles (Fig. $6 B, C ; n=4 \mathrm{LHA}^{\text {Vgat }}$ Control; $n=8$ LHA $^{\text {Vgat }}$ DREADD-Gq; $\left.T_{(10)}=-2.273, p<0.05\right)$. These results provide strong support for a physiological distinction between LHA ${ }^{\text {Gal }}$ and the larger LHA ${ }^{G A B A}$ neuron population.

\section{Discussion}

The LHA modulates food reward and consumption behaviors; however, the exact role of anatomically and molecularly distinct regions of LHA neurons and their contribution to these behaviors still remain unclear. Our data confirm that LHA neurons and specifically LHA $^{G A B A}$ neurons modulate food reward and consumption behaviors. In addition, we distinguish the larger population of LHA ${ }^{G A B A}$ neurons from $\mathrm{LHA}^{\mathrm{Gal}}$ neurons, which represents a subpopulation of LHA $^{G A B A}$ neurons that does not innervate the VTA directly. Overall our data demonstrate that activation of $\mathrm{LHA}^{\mathrm{Gal}}$ neurons is sufficient to enhance the motivation to work for food and thus does not require direct VTA innervation. In contrast, activation of $\mathrm{LHA}^{\text {Gal }}$ neurons did not modulate overall food consumption and thus may require direct VTA interaction. This further suggests that VTA- 


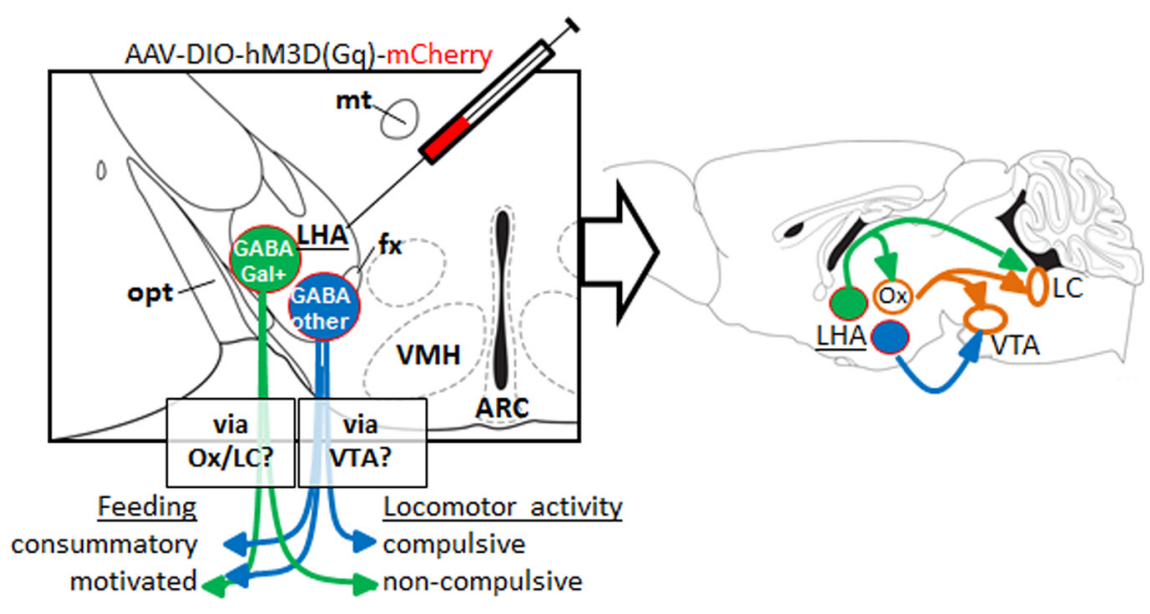

Figure 7. Proposed circuit for $L H A{ }^{G a l}$ and $L H A A^{G A B A}$ behavioral phenotypes. We propose that $L H A A^{G A B A / g a l a n i n}$-positive neurons modulate motivated feeding via non-VTA projections such as the LC or Hcrt/0x population within the LHA. Nongalaninergic LHA ${ }^{G A B A}$ neurons modulate consummatory behavior along with compulsive behaviors via VTA projections. LHA, lateral hypothalamic area; ARC, arcuate nucleus; VMH, ventromedial hypothalamus; fx, fornix; opt, optic tract; mt, mammillothalamic tract; VTA, ventral tegmental area; Hcrt/0x, Hypocretin/orexin; LC, locus coeruleus; Gal, galanin.

projecting LHA ${ }^{G A B A}$ neurons may mediate the homeostatic food consumption independently of motivational food seeking. While our study did not directly address the possible role of the neuropeptide galanin per se, our study is the first to use genetically targeted approaches to investigate the contribution of LHA ${ }^{\text {Gal }}$ circuitry to modulate behavioral output.

\section{Modulation of food seeking versus food consumption}

Recent studies demonstrated that LHA ${ }^{G A B A}$ neurons are potent modulators of feeding (Jennings et al., 2015; Nieh et al., 2015; Barbano et al., 2016) where activation of overall LHA ${ }^{G A B A}$ neurons induced food reward and consumption (Jennings et al., 2015), while select activation of $\mathrm{LHA}^{\mathrm{GABA}}>$ VTA circuits exclusively induced food consumption, but not food reward (Nieh et al., 2015). These data suggested that non-VTA-projecting LHA ${ }^{G A B A}$ neurons are responsible for mediating food reward. We show that activation of $\mathrm{LHA}^{\mathrm{Gal}}$ neurons is sufficient to selectively enhance food reward, but not food consumption. Collectively our data provide evidence that non-VTA-projecting LHA $^{\text {Gal }}$ neurons represent LHA ${ }^{\text {GABA }}$ neurons that mediate food-reward behavior and can be contrasted to VTAprojecting LHA $^{G A B A}$ neurons that promote food consumption.

It should be noted that $\mathrm{LHA}^{\mathrm{Gal}}$ neurons strongly innervate LHA orexin neurons as well as noradrenergic LC neurons (Laque et al., 2015), which modulate both goal-directed and motivated behavior (Harris et al., 2005; Hofmeister and Sterpenich, 2015). Orexin-mediated food reward involves at least in part projections to the VTA (Peyron et al., 1998; Korotkova et al., 2003; Zheng et al., 2007; Kempadoo et al., 2013). Nevertheless, the dense orexin input to the LC that regulates arousal (Bourgin et al., 2000) could certainly contribute to the overall effect on motivated behavior and food reward and this possibility will need to be addressed in future studies.

We also tested palatable food intake after stimulation of either LHA $^{\text {Gal }}$ or LHA ${ }^{G A B A}$ neurons, but we were unable to confirm increased consumption of palatable, fat-rich Ensure solution with LHA ${ }^{G A B A}$ neurons (Jennings et al., 2015). However, due to the large consumption of Ensure $(2-3 \mathrm{ml})$ per test session, we cannot rule out the possibility that this is due to a ceiling effect that prevents detection of increased consumption. Together our data suggest that motivated behavior and overall chow intake is regulated by distinct LHA neuronal populations and that motivated feeding does not require direct interaction with VTA neurons.

\section{LHA $^{\text {Gal }}$ and LHA ${ }^{\text {GABA }}$ neuronal activation both increase locomotor activity, with differing behavioral characteristics}

Chemogenetic activation of both $\mathrm{LHA}^{\mathrm{Gal}}$ and LHA ${ }^{G A B A}$ neurons robustly increased locomotor activity, which was most pronounced in the LHA ${ }^{G A B A}$ DREADD-Gq mice. Recent studies using chemogenetic and optogenetic methods to investigate LHA $^{G A B A}$ neurons did not evaluate locomotor behavior (Jennings et al., 2015; Nieh et al., 2015). Locomotor activity may depend on a variety of behavioral changes. While physical activity and exercise is tightly bound to changes in energy expenditure, other locomotor behaviors may rather indicate arousal, grooming, and anxiety, as well as compulsive behaviors. Yet, routine locomotor assessment (beam breaks, telemetry) is not sufficient to understand the cause for changes in locomotor activity.

Indeed, activation of $\mathrm{LHA}^{\mathrm{Gal}}$ or LHA ${ }^{G A B A}$ neurons similarly induced locomotor activity, even though we observed visually distinct behavior. Activation of $\mathrm{LHA}^{\text {Gal }}$ neurons increased a range of typical mouse behavior, such as grooming, digging in the bedding, and walking, with frequent transitions from one behavior to the other. In contrast, activation of GABA neurons resulted in repetitive behavior dependent on the environment (e.g., availability of marbles), but was characterized by compulsive maintenance of one behavior over a long time (e.g., digging, gnawing).

We speculate that the difference in locomotor behaviors is also based on the presence of LHA $>$ VTA projections that seem to promote compulsive-like locomotor behavior, while the absence of LHA > VTA projections diminish compulsive locomotor behavior. This hypothesis is further supported by numerous publications linking increased dopamine release in the nucleus accumbens to obsessive-compulsive and repetitive behavior as well as overall locomotor activity (Molloy and Waddington, 1987; White et al., 1988; Colle and Wise, 1991; Berridge et al., 2005; Aliane et al., 2009; Kim et al., 2015). Indeed, chemogenetic activation of GABAergic LHA neurotensin neurons that predominantly act via VTA projections induces dopamine-dependent locomotor activity (Patterson et al., 2015) and also increases food-reward behavior (Leinninger et al., 2011; Kempadoo et al., 2013; Opland et al., 2013), even though compulsivity was not tested in these studies.

Increased locomotor activity may also reflect arousal, as recently suggested by data showing that LHA ${ }^{G A B A}$ neurons innervate the ventral medial preoptic area (VLPO; Venner et al., 2016). Future studies will have to determine whether $\mathrm{LHA}^{\text {Gal }}>$ orexin versus $L_{H A}{ }^{G A B A}>$ VLPO circuits contribute to different aspects of arousal and locomotor activity and whether this may also differentially affect repetitive compulsive behavior. Several studies mentioned induction of compulsive-like behaviors following chemogenetic or optogenetic activation of LHA ${ }^{G A B A}$ or LHA $^{G A B A}>$ VTA projections (Nieh et al., 2015; Navarro et al., 2016; Venner et al., 2016), so that an LHA > VTA-mediated compulsive behavior is strongly suggested. 


\section{Anatomical considerations and other neurotransmitters}

Our data collected from the $\mathrm{Gal}^{\mathrm{TgGFP}} / \mathrm{Vgat}^{\mathrm{Tom}}$ mice show that only half of LHA ${ }^{\text {Gal }}$ neurons coexpress GABA, so that other neurotransmitters and/or neuropeptides may contribute to the observed effects. LHA ${ }^{\text {Gal }}$ and LHA ${ }^{\text {GABA }}$ neurons do not express hypocretin/orexin (Hcrt/Ox) or melanin-concentrating hormone, but do innervate Hcrt/Ox neurons (Jennings et al., 2015; Laque et al., 2015). A portion of LHA ${ }^{\text {Gal }}$ neurons coexpress neurotensin and cocaine-and-amphetamine-regulated transcript, as well as the long-form leptin receptor (LepRb; Laque et al., 2013), which are all mediators of anorexigenic action.

Our previous work suggested that LepRb-expressing LHA ${ }^{\text {Gal }}$ neurons mediate food reward via inhibitory inputs to Hcrt/Ox (Laque et al., 2015), either via inhibitory GABA or galanin signaling (Goforth et al., 2014). However, activation of LHA ${ }^{\text {Gal }}$ neurons induced food reward so that indirect actions of GABAergic $\mathrm{LHA}^{\mathrm{Gal}}$ neurons are likely. Indeed, activation of $\mathrm{LHA}^{\mathrm{Gal}}$ or $\mathrm{LHA}^{\text {Vgat }}$ both seemed to induce cFos in Hcrt/Ox neurons (data not shown), suggesting indirect actions involving disinhibition via interneurons or feedforward mechanisms via effects on the first-order projection sites in other brain regions (e.g., LC or VTA). We further observed strong cFos induction in nonHcrt/Ox neurons, with some of these likely reflecting primary activated LHA ${ }^{\text {Gal }}$ or LHA ${ }^{\text {Vgat }}$ neurons. However, given the extent of cFos-positive non-Hcrt/Ox neurons, we cannot rule out the possibility that other, unidentified LHA populations are equally involved in mediating reward behavior.

Thus, the role of Hcrt/Ox neurons to mediate LHA ${ }^{\text {Gal }}$ signals requires further investigation. LHA $^{\text {Gal }}$ neurons, similar to Hcrt/Ox neurons, strongly innervate the LC (Carter et al., 2012; Laque et al., 2015). The Hcrt/Ox > LC axis mediates arousal (Carter et al., 2012) and the LC is generally associated with the modulation of goal-directed behavior (Usher et al., 1999; Bouret and Richmond, 2015). Thus, further studies will have to clarify whether the LC is a relevant mediator of the observed effects in food-reward and locomotor activity.

Recent studies have shown that within the LHA ${ }^{G A B A}$ population, discrete groups of GABA neurons are differentially activated during select feeding behaviors (Jennings et al., 2015), suggesting the existence of functionally distinct neuronal populations. Indeed, discrete populations of LHA ${ }^{G A B A}>$ VTA terminals respond differentially to varying degrees of optogenetic parameters, such as laser frequency and duration (Barbano et al., 2016). While LHA $>$ VTA projections generally enhanced food reward and consumption, LHA ${ }^{G A B A}>$ VTA projection selectively modulated food consumption, indicating that non-VTA-projecting LHA ${ }^{\text {GABA }}$ neurons are required for LHA ${ }^{\text {GABA }}$-induced food reward.

Our data indicate that LHA ${ }^{\text {Gal }}$ neurons represent these nonVTA-projecting $\mathrm{LHA}^{G A B A}$ neurons that selectively modulate food reward. Furthermore, activation of LHA ${ }^{G A B A}$ neurons, but not LHA ${ }^{\text {Gal }}$ neurons, induced compulsive locomotor activity. We further propose that compulsive locomotor behavior requires LHA ${ }^{G A B A}$ innervation of the VTA, which is supported by Nieh and colleagues reporting that activation of LHA ${ }^{G A B A}>$ VTA terminals increased maladaptive gnawing behavior (Nieh et al., 2015).

In summary, we show that LHA ${ }^{\text {Gal }}$ neurons represent a population of LHA ${ }^{G A B A}$ neurons that do not directly innervate the VTA and are sufficient to modulate food reward. We propose that the effect of LHA ${ }^{\text {Gal }}$ stimulation on motivated behavior relies on direct or indirect projections to Hcrt/Ox and/or the LC (Fig. 7). Further, $\mathrm{LHA}^{\mathrm{Gal}}$ neurons induce motivated feeding and locomotor activity without changes in daily caloric intake or compulsive/ repetitive behaviors, which could have important implications for treatment strategies for feeding disorders and compulsive behaviors.

\section{References}

Abramoff MD, Magalhaes PJ, Ram SJ (2004) Image Processing with ImageJ. Biophotonics Int 11:36-42.

Aliane V, Pérez S, Nieoullon A, Deniau JM, Kemel ML (2009) Cocaine-induced stereotypy is linked to an imbalance between the medial prefrontal and sensorimotor circuits of the basal ganglia. Eur J Neurosci 30:1269-1279. CrossRef Medline

Anand BK, Brobeck JR (1951) Hypothalamic control of food intake in rats and cats. Yale J Biol Med 24:123-140. Medline

Angoa-Perez M, Kane MJ, Briggs DI, Francescutti DM, Kuhn DM (2013) Marble burying and nestlet shredding as tests of repetitive, compulsivelike behaviors in mice. J Vis Exp 50978. CrossRef Medline

Barbano MF, Wang HL, Morales M, Wise RA (2016) Feeding and reward are differentially induced by activating GABAergic lateral hypothalamic projections to VTA. J Neurosci 36:2975-2985. CrossRef Medline

Berridge KC, Aldridge JW, Houchard KR, Zhuang X (2005) Sequential super-stereotypy of an instinctive fixed action pattern in hyperdopaminergic mutant mice: a model of obsessive compulsive disorder and Tourette's. BMC Biol 3:4. CrossRef Medline

Berthoud HR, Münzberg H (2011) The lateral hypothalamus as integrator of metabolic and environmental needs: from electrical self-stimulation to opto-genetics. Physiol Behav 104:29-39. CrossRef Medline

Bonnavion P, Mickelsen LE, Fujita A, de Lecea L, Jackson AC (2016) Hubs and spokes of the lateral hypothalamus: cell types, circuits and behaviour. J Physiol 594:6443-6462. CrossRef Medline

Bouret S, Richmond BJ (2015) Sensitivity of locus ceruleus neurons to reward value for goal-directed actions. J Neurosci 35:4005-4014. CrossRef Medline

Bourgin P, Huitrón-RésendizS, Spier AD, Fabre V, Morte B, Criado JR, Sutcliffe JG, Henriksen SJ, de Lecea L (2000) Hypocretin-1 modulates rapid eye movement sleep through activation of locus coeruleus neurons. J Neurosci 20:7760-7765. Medline

Carter ME, Brill J, Bonnavion P, Huguenard JR, Huerta R, de Lecea L (2012) Mechanism for hypocretin-mediated sleep-to-wake transitions. Proc Natl Acad Sci U S A 109:E2635-E2644. CrossRef Medline

Colle LM, Wise RA (1991) Circling induced by intra-accumbens amphetamine injections. Psychopharmacology (Berl) 105:157-161. CrossRef Medline

Deacon RM (2006) Digging and marble burying in mice: simple methods for in vivo identification of biological impacts. Nat Protoc 1:122-124. CrossRef Medline

Goforth PB, Leinninger GM, Patterson CM, Satin LS, Myers MG Jr (2014) Leptin acts via lateral hypothalamic area neurotensin neurons to inhibit orexin neurons by multiple GABA-independent mechanisms. J Neurosci 34:11405-11415. CrossRef Medline

Hahn JD, Swanson LW (2010) Distinct patterns of neuronal inputs and outputs of the juxtaparaventricular and suprafornical regions of the lateral hypothalamic area in the male rat. Brain Res Rev 64:14-103. CrossRef Medline

Harris GC, Wimmer M, Aston-Jones G (2005) A role for lateral hypothalamic orexin neurons in reward seeking. Nature 437:556-559. CrossRef Medline

Hofmeister J, Sterpenich V (2015) A role for the locus ceruleus in reward processing: encoding behavioral energy required for goal-directed actions. J Neurosci 35:10387-10389. CrossRef Medline

Jennings JH, Ung RL, Resendez SL, Stamatakis AM, Taylor JG, Huang J, Veleta K, Kantak PA, Aita M, Shilling-Scrivo K, Ramakrishnan C, Deisseroth K, Otte S, Stuber GD (2015) Visualizing hypothalamic network dynamics for appetitive and consummatory behaviors. Cell 160:516-527. CrossRef Medline

Kempadoo KA, Tourino C, Cho SL, Magnani F, Leinninger GM, Stuber GD, Zhang F, Myers MG, Deisseroth K, de Lecea L, Bonci A (2013) Hypothalamic neurotensin projections promote reward by enhancing glutamate transmission in the VTA. J Neurosci 33:7618-7626. CrossRef Medline

Kim IH, Rossi MA, Aryal DK, Racz B, Kim N, Uezu A, Wang F, Wetsel WC, Weinberg RJ, Yin H, Soderling SH (2015) Spine pruning drives antipsychotic-sensitive locomotion via circuit control of striatal dopamine. Nat Neurosci 18:883-891. CrossRef Medline 
Korotkova TM, Sergeeva OA, Eriksson KS, Haas HL, Brown RE (2003) Excitation of ventral tegmental area dopaminergic and nondopaminergic neurons by orexins/hypocretins. J Neurosci 23:7-11. Medline

Laque A, Zhang Y, Gettys S, Nguyen TA, Bui K, Morrison CD, Münzberg H (2013) Leptin receptor neurons in the mouse hypothalamus are colocalized with the neuropeptide galanin and mediate anorexigenic leptin action. Am J Physiol Endocrinol Metab 304:E999-E1011. CrossRef Medline

Laque A, Yu S, Qualls-Creekmore E, Gettys S, Schwartzenburg C, Bui K, Rhodes C, Berthoud HR, Morrison CD, Richards BK, Münzberg H (2015) Leptin modulates nutrient reward via inhibitory galanin action on orexin neurons. Mol Metab 4:706-717. CrossRef Medline

Leinninger GM, Jo YH, Leshan RL, Louis GW, Yang H, Barrera JG, Wilson H, Opland DM, Faouzi MA, Gong Y, Jones JC, Rhodes CJ, Chua S Jr, Diano S, Horvath TL, Seeley RJ, Becker JB, Münzberg H, Myers MG Jr (2009) Leptin acts via leptin receptor-expressing lateral hypothalamic neurons to modulate the mesolimbic dopamine system and suppress feeding. Cell Metab 10:89-98. CrossRef Medline

Leinninger GM, Opland DM, Jo YH, Faouzi M, Christensen L, Cappellucci LA, Rhodes CJ, Gnegy ME, Becker JB, Pothos EN, Seasholtz AF, Thompson RC, Myers MG Jr (2011) Leptin action via neurotensin neurons controls orexin, the mesolimbic dopamine system and energy balance. Cell Metab 14:313-323. CrossRef Medline

Melander T, Hökfelt T, RökaeusA, Cuello AC, Oertel WH, Verhofstad A, Goldstein M (1986) Coexistence of galanin-like immunoreactivity with catecholamines, 5-hydroxytryptamine, GABA and neuropeptides in the rat CNS. J Neurosci 6:3640-3654. Medline

Molloy AG, Waddington JL (1987) Pharmacological characterization in the rat of grooming and other behavioural responses to the D1 dopamine receptor agonist R-SK\&F 38393. J Psychopharmacol 1:177-183. CrossRef Medline

Nakajima K, Cui Z, Li C, Meister J, Cui Y, Fu O, Smith AS, Jain S, Lowell BB, Krashes MJ, Wess J (2016) Gs-coupled GPCR signalling in AgRP neurons triggers sustained increase in food intake. Nat Commun 7:10268. CrossRef Medline

Navarro M, Olney JJ, Burnham NW, Mazzone CM, Lowery-Gionta EG, Pleil KE, Kash TL, Thiele TE (2016) Lateral hypothalamus GABAergic neurons modulate consummatory behaviors regardless of the caloric content or biological relevance of the consumed stimuli. Neuropsychopharmacology 41:1505-1512. CrossRef Medline

Nieh EH, Matthews GA, Allsop SA, Presbrey KN, Leppla CA, Wichmann R, Neve R, Wildes CP, Tye KM (2015) Decoding neural circuits that control compulsive sucrose seeking. Cell 160:528-541. CrossRef Medline

Olds J, Milner P (1954) Positive reinforcement produced by electrical stimulation of septal area and other regions of rat brain. J Comp Physiol Psychol 47:419-427. CrossRef Medline

Opland D, Sutton A, Woodworth H, Brown J, Bugescu R, Garcia A, Christensen L, Rhodes C, Myers M Jr, Leinninger G (2013) Loss of neurotensin receptor-1 disrupts the control of the mesolimbic dopamine system by leptin and promotes hedonic feeding and obesity. Mol Metab 2:423-434. CrossRef Medline
Patterson CM, Wong JM, Leinninger GM, Allison MB, Mabrouk OS, Kasper CL, Gonzalez IE, Mackenzie A, Jones JC, Kennedy RT, Myers MG Jr (2015) Ventral tegmental area neurotensin signaling links the lateral hypothalamus to locomotor activity and striatal dopamine efflux in male mice. Endocrinology 156:1692-1700. CrossRef Medline

Paxinos G, Franklin KBJ (2004) The mouse brain in stereotaxic coordinates. New York: Elsevier Science.

Peyron C, Tighe DK, van den Pol AN, de Lecea L, Heller HC, Sutcliffe JG, Kilduff TS (1998) Neurons containing hypocretin (orexin) project to multiple neuronal systems. J Neurosci 18:9996-10015. Medline

Rezai-Zadeh K, Yu S, Jiang Y, Laque A, Schwartzenburg C, Morrison CD, Derbenev AV, Zsombok A, Münzberg H (2014) Leptin receptor neurons in the dorsomedial hypothalamus are key regulators of energy expenditure and body weight, but not food intake. Mol Metab 3:681-693. CrossRef Medline

Richardson NR, Roberts DC (1996) Progressive ratio schedules in drug selfadministration studies in rats: a method to evaluate reinforcing efficacy. J Neurosci Methods 66:1-11. CrossRef Medline

Sherin JE, Elmquist JK, Torrealba F, Saper CB (1998) Innervation of histaminergic tuberomammillary neurons by GABAergic and galaninergic neurons in the ventrolateral preoptic nucleus of the rat. J Neurosci 18: 4705-4721. Medline

Swanson LW, Sanchez-Watts G, Watts AG (2005) Comparison of melaninconcentrating hormone and hypocretin/orexin mRNA expression patterns in a new parceling scheme of the lateral hypothalamic zone. Neurosci Lett 387:80-84. CrossRef Medline

Usher M, Cohen JD, Servan-Schreiber D, Rajkowski J, Aston-Jones G (1999) The role of locus coeruleus in the regulation of cognitive performance. Science 283:549-554. CrossRef Medline

Venner A, Anaclet C, Broadhurst RY, Saper CB, Fuller PM (2016) A novel population of wake-promoting GABAergic neurons in the ventral lateral hypothalamus. Curr Biol 26:2137-2143. CrossRef Medline

Vong L, Ye C, Yang Z, Choi B, Chua S Jr, Lowell BB (2011) Leptin action on GABAergic neurons prevents obesity and reduces inhibitory tone to POMC neurons. Neuron 71:142-154. CrossRef Medline

White FJ, Bednarz LM, Wachtel SR, Hjorth S, Brooderson RJ (1988) Is stimulation of both D1 and D2 receptors necessary for the expression of dopamine-mediated behaviors? Pharmacol Biochem Behav 30:189-193. CrossRef Medline

Yu S, Qualls-Creekmore E, Rezai-Zadeh K, Jiang Y, Berthoud HR, Morrison CD, Derbenev AV, Zsombok A, Münzberg H (2016) Glutamatergic preoptic area neurons that express leptin receptors drive temperaturedependent body weight homeostasis. J Neurosci 36:5034-5046. CrossRef Medline

Zheng H, Patterson LM, Berthoud HR (2007) Orexin signaling in the ventral tegmental area is required for high-fat appetite induced by opioid stimulation of the nucleus accumbens. J Neurosci 27:11075-11082. CrossRef Medline 